\title{
A new stepwise carbon cycle data assimilation system using multiple data streams to constrain the simulated land surface carbon cycle
}

\author{
Philippe Peylin $^{1}$, Cédric Bacour ${ }^{2}$, Natasha MacBean ${ }^{1}$, Sébastien Leonard ${ }^{1}$, Peter Rayner ${ }^{1,3}$, Sylvain Kuppel ${ }^{1,4}$, \\ Ernest Koffi ${ }^{1}$, Abdou Kane ${ }^{1}$, Fabienne Maignan ${ }^{1}$, Frédéric Chevallier $^{1}$, Philippe Ciais ${ }^{1}$, and Pascal Prunet ${ }^{2}$ \\ ${ }^{1}$ Laboratoire des Sciences du Climat et de l'Environnement, UMR 8212 CEA-CNRS-UVSQ, \\ 91191 Gif-sur-Yvette CEDEX, France \\ ${ }^{2}$ Noveltis, Parc Technologique du Canal, 2 avenue de l'Europe, 31520 Ramonville-Saint-Agne, France \\ ${ }^{3}$ University of Melbourne, 3010, Vic, Melbourne, Australia \\ ${ }^{4}$ Grupo de Estudios Ambientales, IMASL-CONICET/Universidad Nacional de San Luis, San Luis, Argentina \\ Correspondence to: Philippe Peylin (peylin@1sce.ipsl.fr)
}

Received: 14 January 2016 - Published in Geosci. Model Dev. Discuss.: 28 January 2016

Revised: 19 August 2016 - Accepted: 30 August 2016 - Published: 20 September 2016

\begin{abstract}
Large uncertainties in land surface models (LSMs) simulations still arise from inaccurate forcing, poor description of land surface heterogeneity (soil and vegetation properties), incorrect model parameter values and incomplete representation of biogeochemical processes. The recent increase in the number and type of carbon cycle-related observations, including both in situ and remote sensing measurements, has opened a new road to optimize model parameters via robust statistical model-data integration techniques, in order to reduce the uncertainties of simulated carbon fluxes and stocks. In this study we present a carbon cycle data assimilation system that assimilates three major data streams, namely the Moderate Resolution Imaging Spectroradiometer (MODIS)-Normalized Difference Vegetation Index (NDVI) observations of vegetation activity, net ecosystem exchange (NEE) and latent heat (LE) flux measurements at more than 70 sites (FLUXNET), as well as atmospheric $\mathrm{CO}_{2}$ concentrations at 53 surface stations, in order to optimize the main parameters (around 180 parameters in total) of the Organizing Carbon and Hydrology in Dynamics Ecosystems (ORCHIDEE) LSM (version 1.9.5 used for the Coupled Model Intercomparison Project Phase 5 (CMIP5) simulations). The system relies on a stepwise approach that assimilates each data stream in turn, propagating the information gained on the parameters from one step to the next.

Overall, the ORCHIDEE model is able to achieve a consistent fit to all three data streams, which suggests that current LSMs have reached the level of development to assim-
\end{abstract}

ilate these observations. The assimilation of MODIS-NDVI (step 1) reduced the growing season length in ORCHIDEE for temperate and boreal ecosystems, thus decreasing the global mean annual gross primary production (GPP). Using FLUXNET data (step 2) led to large improvements in the seasonal cycle of the NEE and LE fluxes for all ecosystems (i.e., increased amplitude for temperate ecosystems). The assimilation of atmospheric $\mathrm{CO}_{2}$, using the general circulation model (GCM) of the Laboratoire de Météorologie Dynamique (LMDz; step 3), provides an overall constraint (i.e., constraint on large-scale net $\mathrm{CO}_{2}$ fluxes), resulting in an improvement of the fit to the observed atmospheric $\mathrm{CO}_{2}$ growth rate. Thus, the optimized model predicts a land $\mathrm{C}$ (carbon) sink of around 2.2 $\mathrm{PgC} \mathrm{yr}^{-1}$ (for the 2000-2009 period), which is more compatible with current estimates from the Global Carbon Project (GCP) than the prior value. The consistency of the stepwise approach is evaluated with back-compatibility checks. The final optimized model (after step 3) does not significantly degrade the fit to MODISNDVI and FLUXNET data that were assimilated in the first two steps, suggesting that a stepwise approach can be used instead of the more "challenging" implementation of a simultaneous optimization in which all data streams are assimilated together. Most parameters, including the scalar of the initial soil carbon pool size, changed during the optimization with a large error reduction. This work opens new perspectives for better predictions of the land carbon budgets. 


\section{Introduction}

Atmospheric $\mathrm{CO}_{2}$ concentrations have increased at an unprecedented rate over the last few decades, predominantly due to anthropogenic fossil fuel and cement emissions, as well as land use and land cover change (LULCC). The oceans and the terrestrial biosphere have absorbed $\mathrm{CO}_{2}$, removing on average $50 \%$ of anthropogenic emissions from the atmosphere. However, knowledge about the exact location of sources and sinks of carbon (C) and the driving mechanisms is still lacking. Land surface models (LSMs) can be used to improve our understanding of the spatiotemporal patterns of sources and sinks, as well as for attributing changes due to $\mathrm{CO}_{2}$, climate variability and other environmental drivers. However, the spread in the model predictions of terrestrial net $\mathrm{C}$ (carbon) exchange currently has the same order of magnitude as the uncertainty of the terrestrial $\mathrm{C}$ budget estimated as the residual of the other carbon cycle components (Le Quére et al., 2015). In addition to uncertainties in the mean global annual terrestrial $\mathrm{C}$ budget and its trend over time (Sitch et al., 2015), there remain strong discrepancies between LSMs in their predictions of regional budgets (Canadell et al., 2013) at seasonal and interannual timescales and in their sensitivity to climate and atmospheric $\mathrm{CO}_{2}$ forcing (Piao et al., 2013).

Uncertainties in model simulations arise from inaccurate forcing, incorrect model parameter values and/or an inadequate or incomplete representation of biogeochemical processes in the model (for example the impact of nutrient limitation on $\mathrm{C}$ fluxes, or $\mathrm{C}$ release related to permafrost thawing). Arguably the best way to improve model predictions is to confront simulations with multiple sources of data within an appropriate and rigorous framework (Prentice et al., 2015). In the last 2 decades significant efforts by the site and satellite observation communities have resulted in a large increase in the number and type of $\mathrm{C}$ cycle-related observations. These data contain some information at various spatial and temporal scales and should be combined together to robustly address different aspects of the models. One way in which these data can be used to better quantify and reduce model uncertainty is by optimizing or calibrating the model parameters via robust statistical model-data fusion (or data assimilation - DA) techniques. In particular a Bayesian inference framework allows us to update our prior knowledge of the parameters based on new information contained in the observations.

There is a long history of using DA techniques for parameter optimization, particularly in geophysics (Tarantola, 1987), but the initial studies in the field of global terrestrial C cycle data assimilation started with the initial study of Fung et al. (1987) and a pioneering work by Knorr and Heimann (1995), who used atmospheric $\mathrm{CO}_{2}$ concentration to constrain the Simple Diagnostic Biosphere Model (SDBM). Later, Kaminski et al. (2002) constrain the seasonal cycle of SDBM with the same data stream. This effort was continued by the original Carbon Cycle Data Assimi- lation System (CCDAS) described in Rayner et al. (2005) and Kaminski et al. (2012), which used both atmospheric $\mathrm{CO}_{2}$ and satellite-derived Fraction of Absorbed Photosynthetic Radiation (FAPAR) data to optimize vegetation productivity by adjusting the $\mathrm{C}$ cycle-related parameters of the Biosphere Energy-Transfer Hydrology (BETHY) model (see a review in Kaminski et al., 2013). Note that although Rayner et al. (2005) did use, in addition to atmospheric $\mathrm{CO}_{2}$ data, soil moisture and radiation fields from an earlier assimilation from a simpler model version, no parameters were passed between the two assimilations and very little comment was made on the consistency between the two assimilations, an important issue that will be central to this paper. Meanwhile substantial efforts have been put into the use of local eddy covariance flux tower measurements of net exchange of $\mathrm{CO}_{2}$ and latent and sensible heat fluxes to optimize photosynthesis, respiration and energy-related parameters of terrestrial ecosystem models, both at individual sites (e.g., Wang et al., 2001, 2007; Williams et al., 2005; Braswell et al., 2005; Knorr and Kattge, 2005; Moore et al., 2008; Ricciuto et al., 2008) and more recently using multiple sites together (hereafter multiple sites) from the global FLUXNET network (e.g., Groenendijk et al., 2011; Kuppel et al., 2012, 2014; Alton, 2013; Xiao et al., 2014). Increasingly the focus in carbon cycle data assimilation is moving towards using multiple different data streams as independent constraints, with the aim of bringing more information at different spatial and temporal scales and constraining several processes at once in order to reduce the likelihood of model equifinality (where multiple sets of parameters achieve the same reduction in modeldata misfit). Recent examples include the combination of in situ eddy covariance flux observations and ground-based information on vegetation structure and $\mathrm{C}$ stocks (Richardson et al., 2010; Ricciuto et al., 2011; Keenan et al., 2012, 2013; Thum et al., 2016), or in situ flux data and satellite FAPAR (Kato et al., 2013; Zobitz et al., 2014; Bacour et al., 2015) or atmospheric $\mathrm{CO}_{2}$ and biomass data using a simple biosphere model (Saito et al., 2014). This is a non-trivial task however, especially when optimizing a complex LSM (see MacBean et al., 2016), which has many parameters acting from local to global scales.

When assimilating multiple different data streams we have two options: (i) to optimize the model with each data stream in turn, and to propagate the information gained on the parameter values from one step to the next (hereafter referred to as "stepwise" assimilation), or (ii) to include all data streams together in the same optimization (hereafter referred to as "simultaneous" assimilation). Kaminski et al. (2012) suggested that it is essential to perform a consistent, simultaneous assimilation that includes all data streams in the same optimization. It is important to note that this is an implementation question. Tarantola (2005) recast the fundamentals of the approach as the conjunction or multiplication of probability densities. This multiplication is associative so it makes no difference whether it is performed in one step or several 
(and whether the system is linear or not). In complex problems such as these, one cannot carry or even describe the full structure of the relevant probability densities, so which approach will work best in each case is unclear. In particular, technical difficulties associated with the different number of observations for each data stream and the characterization of error correlations between them, in addition to computational constraints to run global LSMs, might result in the preference for a stepwise assimilation framework. Additionally, it may be more straightforward, to expose a restricted set of parameters (following a global sensitivity analysis) to each observation type in a stepwise approach to ensure that each data stream constrains only the most relevant parts of the model. This reduces biases from other poorly represented processes caused by inadequate model structure. Note finally that more complex approaches based on random generation of parameter sets, such as the multi-objective approach using the Pareto ranking of several cost functions (e.g., Yapo et al., 1998), are not yet affordable for global LSMs from a computational point of view. For these reasons we follow the stepwise approach in this paper.

We present the first global-scale CCDAS that assimilates three of the main global data streams that have been used to date to understand the terrestrial carbon cycle - atmospheric $\mathrm{CO}_{2}$ concentration, satellite-derived information of vegetation greenness (from the Moderate Resolution Imaging Spectroradiometer, MODIS, instrument) and multi-site eddy covariance net $\mathrm{CO}_{2}$ and latent heat flux measurements (from FLUXNET) - to optimize the parameters of the Organizing Carbon and Hydrology in Dynamics Ecosystems (ORCHIDEE) process-based LSM (Krinner et al., 2005). This study is the first (to our knowledge) to assimilate these three major data streams in a process-based LSM used as the land component of an Earth system model (ESM), the French Institut Pierre Simon Laplace ESM. Two contemporary studies also optimize the parameters of the land component of an ESM; however, Raoult et al. (2016) only used FluxNet observations to optimize the parameters of the Joint UK Land Environment Simulator (JULES) model, while Schürmann et al. (2016) only assimilate two data streams (FAPAR and $\mathrm{CO}_{2}$ ) in the JSBACH (Jena Scheme for BiosphereAtmosphere Coupling in Hamburg) model at coarse resolution $\left(10^{\circ} \times 10^{\circ}\right)$. Note finally that the level of complexity of the ecosystem model (and the spatial resolution) is part of the problem: achieving an optimization with a given model does not guarantee that the framework would work with a more complex or different one.

In this context, the main questions that we aim to answer in this paper are as follows:

i. How and to which extend the optimization of the ORCHIDEE model allows one to fit the three data streams that are considered? ii. Does the stepwise optimization result in a degradation of the fit to other data streams used in the previous steps?

iii. What are the main changes in the optimized parameters when using sequentially these three data streams in a global CCDAS and which processes are constrained?

iv. What are the improvements for the land $\mathrm{C}$ cycle in terms of net/gross fluxes and stocks as a result of multidata stream optimization? What preliminary perspectives can we draw that may help us in improving model predictions of trends, variability and the location of terrestrial C sources and sinks?

Following these objectives, the paper first describes the new ORCHIDEE-CCDAS including the concept, the observations, the models and the optimization approach. We then present the results, including the fit to the data, consistency checks (question $\mathrm{i}$, above) as well as the mean global and regional C cycle budget for the period 2000-2009. The last section discusses issues and perspectives associated with these results.

\section{Methods}

\subsection{ORCHIDEE-CCDAS concept}

We have designed a CCDAS around the ORCHIDEE land surface model (ORCHIDEE-CCDAS, later also referred to as ORCHIDAS for simplicity) that combines a state-of-the-art description of the driving biogeochemical processes within the model with multiple observational constraints in a robust statistical framework, in order to improve the simulation of land carbon fluxes and stocks. The system allows us to retrieve the best estimate, given the observations and prior information, of selected parameters (see Sect. 2.3.3) as well as to evaluate their uncertainty. It relies on a stepwise assimilation of a comprehensive set of three $\mathrm{C}$ cycle-related observations that are representative of small $(100 \mathrm{~m})$ to large (continental) scales (see Sect. 2.2):

- step 1: satellite measurements of vegetation activity using the Normalized Difference Vegetation Index (NDVI) from the MODIS instrument over the 20002008 period for a randomly selected set of sites for boreal and temperate deciduous vegetation types;

- step 2: in situ eddy covariance net $\mathrm{CO}_{2}$ and water (latent heat) flux measurements from the FLUXNET database for a large set of sites, spanning seven different vegetation types;

- step 3: in situ monthly atmospheric surface $\mathrm{CO}_{2}$ concentration measurements from the GLOBALVIEWCO2 database over 3 years (2002-2004). 


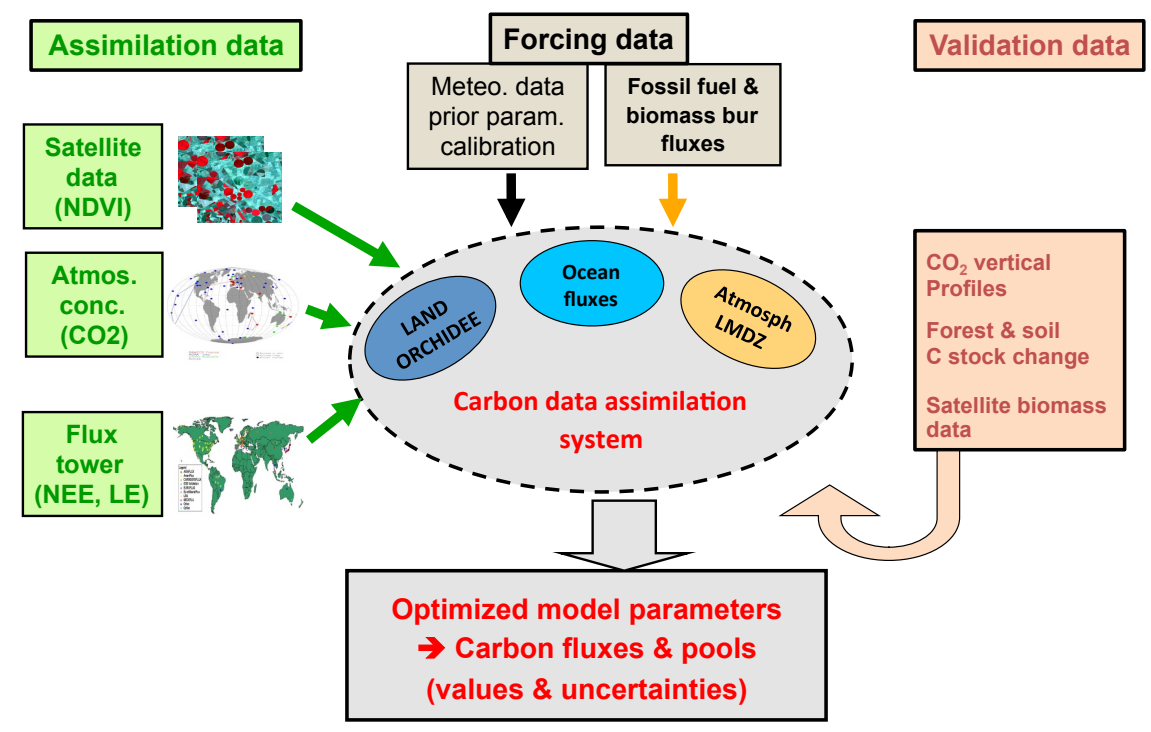

Figure 1. Schematic of the ORCHIDEE Carbon Cycle Data Assimilation System (ORCHIDAS).

The system relies on two models:

- the ORCHIDEE global LSM, whose main C cycle parameters are optimized (see Sect. 2.3);

- the GCM of the Laboratoire de Météorologie Dynamique, $\mathrm{LMDz}$ (see Sect. 2.3), to relate the surface carbon fluxes to atmospheric $\mathrm{CO}_{2}$ concentrations.

The framework combines the different observational data streams within ORCHIDAS in order to optimize selected model parameters using a variational data assimilation system, described in Sect. 2.4. Figure 1 illustrates the structure of the CCDAS and the different components that are involved. Such a framework distinguishes (i) the assimilated observations, (ii) an ensemble of forcing and input data streams, (iii) the models and optimization framework, as well as (iv) an evaluation step, where independent data sets are compared to the optimized model stocks and fluxes. As explained in the introduction, a major feature of the current system is the stepwise approach, in which all data streams are assimilated sequentially (i.e., one after the other). The information retrieved at a given step (retrieved optimal parameter values and associated uncertainty) is propagated to the next step (see Fig. 2 and Sect. 2.4). Note that for simplicity we did not propagate the error correlations in this first implementation of the system, a simplification that appeared sufficient (see the consistency analysis in Sect. 3.2); Sect. 4 also discusses the potential impact of this simplification.

At each step, the parameter optimization relies on a Bayesian framework that explicitly minimizes the difference between the simulated and observed quantities in addition to minimizing the difference between the optimized model parameters and "a priori" values (see Sect. 2.4.2). The dependence of the simulated quantities on the optimized variables

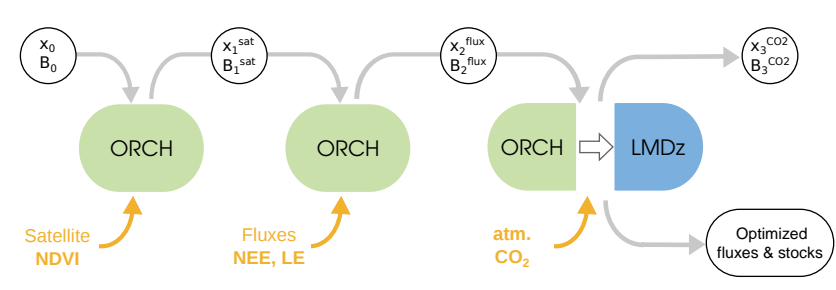

Figure 2. Illustration of the stepwise data assimilation approach used for the assimilation of multiple data streams in the ORCHIDEE-CCDAS. The list of parameters for each step is summarized in Table 1.

is nonlinear, which thus necessitates the use of an iterative algorithm. Note that all components of the surface $\mathrm{C}$ budget need also to be included in the ORCHIDAS, particularly when using atmospheric $\mathrm{CO}_{2}$ measurements, which requires the atmospheric transport model to be prescribed with fossil fuel emissions, $\mathrm{CO}_{2}$ fluxes associated with biomass burning and ocean $\mathrm{CO}_{2}$ fluxes (see Sect. 2.5) in addition to net ecosystem exchange (NEE) from ORCHIDEE.

\subsection{Assimilated observations}

\subsubsection{MODIS-NDVI}

MODIS collection 5 obtained from surface reflectance data (from 2000 to 2008) in the red (R) and near-infrared (NIR) bands at $5 \mathrm{~km}$ resolution (CMG) are used to optimize the phenology-related parameters of ORCHIDEE in the first step. The R and NIR data were processed to correct for directional effects following Vermote et al. (2009) and then used to calculate the NDVI, which is assumed to be linearly related to the model FAPAR. The NDVI are then (i) aggregated 
to the $0.72^{\circ}$ spatial resolution of the ERA-Interim meteorological fields that are used to force ORCHIDEE, (ii) interpolated to a daily time series (for practical implementation) and (iii) checked for quality (see MacBean et al., 2015 for details). If there is a gap in the observations of more than 15 days, no interpolation is done (i.e., no data during the gap are assimilated). Figure 3 displays the location of the sites that were selected (see Sect. 2.4.1).

\subsubsection{Eddy covariance flux data}

Eddy covariance flux measurements of net surface $\mathrm{CO}_{2}$ flux - hereafter referred to as NEE and latent heat (LE) flux from 78 observation sites of a network of regional networks (FLUXNET; see Fig. 3) are used to constrain ecosystem physiology and fast C-related processes at daily to seasonal timescales in ORCHIDEE in the second step. We use qualitychecked and gap-filled data from a global synthesis called the La Thuile data set (Papale, 2006). In order to avoid dealing with the large error correlations in the half-hourly data (see Lasslop et al., 2008), daily mean values of NEE and LE are used in the ORCHIDAS. Days with less than $80 \%$ of the half-hourly data are left out of the assimilation. The selection of the sites and the data processing (gap-filling, correction for energy balance closure) are detailed in Kuppel et al. (2014). Note that uncertainties due to incomplete sampling of the diurnal cycle are likely very small (less than $5 \%$ ) as the error in the gap-filling procedure is usually less than $20 \%$ (Lasslop et al., 2008).

\subsubsection{Atmospheric $\mathrm{CO}_{2}$ concentrations}

Atmospheric $\mathrm{CO}_{2}$ concentration measurements were taken from an ensemble of selected surface stations around the world (Fig. 3). The spatial concentration gradients relate to the integral of the fluxes over large areas and thus allow the optimization of large-scale global patterns of carbon fluxes. These data were taken from the NOAA Earth System Laboratory (ESRL) GLOBALVIEW-CO2 collaborative product (GLOBALVIEW-CO2, 2013) and averaged to monthly means. We assimilated the monthly values for 53 sites for the 2002-2004 period inclusive in the last step of the assimilation system. Such a restricted period (3 years only) was chosen for practical reasons (computing resources) while constructing the ORCHIDAS system. The station locations, indicated in Fig. 3, favor the background conditions; i.e., the surrounding air masses are only weakly influenced by local continental sources, such as power plants. The choice of monthly mean is related to the use of pre-calculated transport fields with LMDz (see Sect. 2.3.2). We also used additional sites to evaluate the result of the optimization (locations indicated in Fig. 3): this included 17 continental sites that are more directly influenced by local fluxes potentially not well captured at the considered LMDz spatial resolution and 7 sites from Pacific Ocean cruises that were not in-

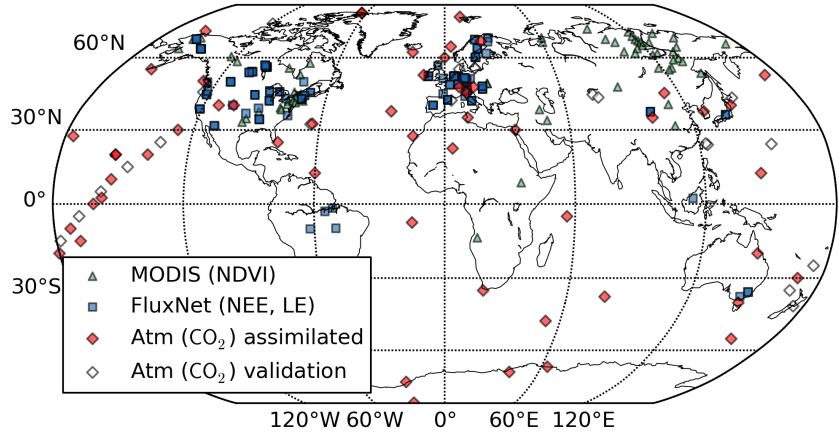

Figure 3. Location of the different observations used for each data stream assimilated in the system: MODIS-NDVI measurements, FLUXNET sites with NEE and LE measurements and atmospheric $\mathrm{CO}_{2}$ stations (both the sites that are assimilated and the sites used for the validation).

cluded in the optimization in order not to overweight that the data contribution from that particular region. Note that we did not considered free troposphere aircraft data or column integrated measurements (TCCON sites) in this evaluation, although they are less sensitive to biases in the planetary boundary layer representation, given that (i) we are using pre-calculated transport fields previously computed at surface stations only and (ii) a few scarce free tropospheric data sets will not bring much more information to the additional surface stations.

\subsection{Models and optimized parameters}

\subsubsection{ORCHIDEE land surface model}

In this study we use the ORCHIDEE process-oriented land surface model (Krinner et al., 2005), which computes water, carbon and energy balances at the land surface on a halfhourly time step, using a mechanistic description of the physical and biogeochemical processes (see, http://labex.ipsl.fr/ orchidee/). The model describes the exchange of carbon and water at the leaf level, the allocation of carbon within plant compartments (leaves, roots, heartwood and sapwood), the autotrophic respiration, the production of litter, the plant mortality and the degradation of soil organic matter (CENTURY model; Parton et al., 1988). The hydrological processes for the soil reservoir rely on a double bucket scheme (Ducoudré et al., 1993). The link between the water and carbon modules is via photosynthesis, which is based on the leaf-scale equations of Farquhar et al. (1980) for $\mathrm{C}_{3}$ plants, and Collatz et al. (1992) for C4 plants, that are then integrated over the canopy by assuming an exponential attenuation of light. The FAPAR by each layer of the canopy is calculated from the leaf area index (LAI) following a Beer-Lambert extinction law (Bacour et al., 2015).

ORCHIDEE uses the concept of the plant functional type (PFT) to describe the vegetation distribution, with 13 PFTs 
(including bare soil) that can co-exist in each grid cell. Except for the phenology (see a recent description in MacBean et al., 2015), the equations governing the different processes are generic, but with specific parameter values for each PFT. Detailed descriptions of model equations can be found in numerous publications (see for instance Krinner et al., 2005). ORCHIDEE can be run at either global scale on a grid, or at site level using point-scale surface meteorological forcing variables. It is the land surface component of the Institut Pierre Simon Laplace (IPSL) Earth system model, and the version that we used corresponds to Coupled Model Intercomparison Project Phase 5 (CMIP5) simulations in the IPCC 5th Assessment Report (Dufresne et al., 2013). However, in this study the model is run offline using the ERAInterim 3-hourly near-surface meteorological forcing fields (Dee et al., 2011) aggregated at the spatial resolution of the atmospheric transport model for the global simulations $\left(2.5^{\circ} \times 3.75^{\circ}\right.$; see Sect. 2.3.2). However, when we assimilate in situ flux data in the second step, we force the model with the gap-filled half-hourly meteorological data measured at each site. The global PFT map was derived from the highresolution IGBP AVHRR land data set (Vérant et al., 2004). The carbon pools are brought to equilibrium (spin-up procedure) for both site and global-scale simulations by cycling the available meteorological forcing over several millennia, to ensure that the long-term net carbon flux is close to zero. For the global simulation in the third step, we spun-up the model recycling the 1989-1998 meteorology and then used a transient simulation from 1990 to 2001 with changing climate (ERA-Interim) and increasing $\mathrm{CO}_{2}$, before starting the optimization with atmospheric data over 2002-2004. For the site simulations (i.e., the assimilation of flux data), we recycled the available in situ meteorological forcing to spinup the model, with present-day $\mathrm{CO}_{2}$. Note that the use of soil carbon data, such as from the Harmonized World Soil Database (as well as aboveground biomass data), to initialize the model is not straightforward and represents a challenge to keep the internal model consistency, given that the three soil carbon reservoirs of the CENTURY model are in balance with all components of the model, in particular the input through the different litter pools. Computational and scientific issues to avoid a spin-up approach are still under investigation with ORCHIDEE (see discussion section).

\subsubsection{LMDz model}

The transport model used in this study is version 3 of the GCM, LMDz (Hourdin and Armengaud, 1999) with a horizontal resolution of $3.75^{\circ}$ (longitude) $\times 2.5^{\circ}$ (latitude) and 19 sigma-pressure layers up to $3 \mathrm{hPa}$. The calculated winds $(u$ and $v$ ) are relaxed to the European Centre for MediumRange Weather Forecasts (ECMWF) reanalysis, ERA-40, meteorological data (Uppala et al., 2005) with a relaxation time of $2.5 \mathrm{~h}$ (guiding) in order to realistically account for large-scale advection (Hourdin et al., 2006). Deep convection is parameterized according to the scheme of Tiedtke (1989) and the turbulent mixing in the planetary boundary layer is based on a local second-order closure formalism. The LMDz GCM model has been widely used to model climate (IPCC, 2007) and its derived transport model has been used for the simulation of chemistry of gas and particles and greenhouse gases distributions (Hauglustaine et al., 2004; Folberth et al., 2005; Bousquet et al., 2005; Rivier et al., 2006). For this study, we used pre-calculated transport fields, as described in Peylin et al. (2005), that correspond to the sensitivity of concentration at each atmospheric site and each month to the surface flux of each model grid cell for each day (often called influence functions). The sensitivities (using interannual winds) were calculated with the "retro-transport" formulation implemented in the LMDz transport model (Hourdin et al., 2006). This approach decreases the computing time of the optimization compared to the use of the full forward LMDz model at each iteration, as the transport is replaced by a matrix multiplication with the vector of surface fluxes. Note that the initial 3-D state of the atmospheric concentrations was defined from Chevallier et al. (2010).

\subsubsection{Parameters optimized}

The optimized parameters are described in Table 1, and their prior values, uncertainty and range are given in Table 2. In the most recent studies using ORCHIDAS at site scales, a large set of ORCHIDEE parameters has been optimized (Kuppel et al., 2014; Santaren et al., 2014; Bacour et al., 2015). In this study a smaller set was chosen, based on a Morris sensitivity analysis (Morris, 1991; results not shown) that determines the sensitivity of the NEE and LE to all model parameters at various FLUXNET sites (for each PFT), in order to reduce the computational cost of the global optimization in step 3 (see Sect. 2.5). We considered nine PFT-dependent and four "global" (i.e., non-PFT-dependent) parameters that control mostly the fast carbon processes (diurnal to seasonal). In addition, we introduced a new parameter, $K_{\text {soilc }}$, to scale the initial values (after spin-up) of the modeled slow and passive soil carbon pools, in order to take account of all the historical effects not accounted for in the model that would result in a disequilibrium of these pools in reality. For the site-specific optimizations with FLUXNET data, we have one $K_{\text {soilC,site }}$ parameter per site. For the global-scale optimization step, we used $30 K_{\text {soilC,reg }}$ parameters corresponding to 30 regions potentially coherent for land use and land management history as well as ecosystem and edaphic properties (see Fig. A2 in the Appendix). The initial soil carbon pools of all pixels within each region were thus scaled by the same value. The prior value for all $K_{\text {soilc }}$ parameters was set to one; i.e., the default state of soil carbon pools is assumed to be in equilibrium.

Overall (including all PFT-dependent parameters), we optimize 16 parameters related to phenology, 36 to photosynthesis, 3 to respiration, 1 to the energy budget, 78 soil $\mathrm{C}$ 
Table 1. Parameters description, generality (PFT dependent, global, specific to FLUXNET sites or for a set of regions) and data stream(s) that were used to constrain them.

\begin{tabular}{|c|c|c|c|}
\hline Parameter & Description & Dependent & Constraint \\
\hline$V_{\text {cmax }}$ & Maximum carboxylation rate $\left(\mu \mathrm{mol} \mathrm{m}{ }^{-2} \mathrm{~s}^{-1}\right)$ & PFT & Flux, $\mathrm{CO}_{2}$ \\
\hline$G_{s, \text { slope }}$ & Ball-Berry slope & PFT & Flux, $\mathrm{CO}_{2}$ \\
\hline$c_{T, \mathrm{opt}}$ & Optimal photosynthesis temperature $\left({ }^{\circ} \mathrm{C}\right)$ & PFT & Flux, $\mathrm{CO}_{2}$ \\
\hline SLA & Specific leaf area $\left(\mathrm{m}^{2} \mathrm{~g}^{-1}\right)$ & PFT & Flux, $\mathrm{CO}_{2}$ \\
\hline$K_{\text {LAI, happy }}$ & LAI threshold to stop using carbohydrate reserves & PFT & Sat, Flux, $\mathrm{CO}_{2}$ \\
\hline$K_{\text {pheno,crit }}$ & $\begin{array}{l}\text { Multiplicative parameter of the threshold that determines the } \\
\text { start of the growing season }\end{array}$ & PFT & Sat, Flux, $\mathrm{CO}_{2}$ \\
\hline$L_{\text {age, } \text { crit }}$ & Average critical age of leaves (days) & PFT & Sat, Flux, $\mathrm{CO}_{2}$ \\
\hline$C_{T, \text { senes }}$ & Temperature threshold for senescence $\left({ }^{\circ} \mathrm{C}\right)$ & PFT & Sat, Flux, $\mathrm{CO}_{2}$ \\
\hline$F_{\text {stress,h }}$ & Parameter reducing the hydric limitation of photosynthesis & PFT & Flux, $\mathrm{CO}_{2}$ \\
\hline $\mathrm{MR}_{\text {offset }}$ & Offset of the temperature dependence of maintenance respiration & Global & Flux, $\mathrm{CO}_{2}$ \\
\hline$Q_{10}$ & Temperature dependency of heterotrophic respiration & Global & Flux, $\mathrm{CO}_{2}$ \\
\hline $\mathrm{HR}_{H \mathrm{c}}$ & Offset of the soil/litter moisture control function & Global & Flux, $\mathrm{CO}_{2}$ \\
\hline$K_{\text {soilC, site }}$ & Multinlicative factor of the initial soil carbon pools & per Site & Flux \\
\hline$K_{\text {soilC,reg }}$ & Multiplicative factor of the initial soil carbon pools & 30 regions & $\mathrm{CO}_{2}$ \\
\hline$K_{\text {albedo }}$ & Multiplicative factor of the vegetation albedo & Global & Flux, $\mathrm{CO}_{2}$ \\
\hline
\end{tabular}

pool scalars (one for each FLUXNET site) and 30 regional soil C pool scalars for the global simulations - a total of 184 parameters $(16,134$ and 86 in step 1, 2 and 3, respectively). Note that the soil C pool multipliers at the FLUXNET sites are independent from the regional $\mathrm{C}$ pool multipliers, as the history of soil carbon over large eco-regions of several millions square kilometers is rather heterogeneous (as it is mainly related to previous land use changes) and, most likely, the FLUXNET sites are not representative of larger regions in terms of the soil carbon disequilibrium. The prior standard deviation for each parameter is equal to $40 \%$ of the parameter range (lower and higher boundaries) prescribed for each parameter following Kuppel et al. (2012). The parameter ranges were specified following expert judgment of their meaning in the ORCHIDEE equations and based on literature reviews or databases (such as the global database of plant traits, TRY; Kattge et al., 2011).

\subsection{System description: a stepwise approach}

\subsubsection{Stepwise assimilation of three data streams}

The ORCHIDAS system relies on a stepwise assimilation of the three data streams described in Sect. 2.2. Figure 2 illustrates the flow of information in this sequential approach:

Step 1 - assimilation of MODIS-NDVI: four parameters related to the seasonal cycle of the vegetation (phenology) are optimized for the temperate and boreal deciduous PFTs (TeBD: temperate broadleaf deciduous, BoND: boreal needleleaf deciduous, BoBD: boreal broadleaf deciduous and $\mathrm{NC}_{3}$; see caption of Table 2). These four deciduous PFTs alone are considered in step 1 in this ORCHIDAS version because the tropical deciduous phenology modules in ORCHIDEE require further modifications to improve the func- tions that control leaf growth and fall in response to water availability (MacBean et al., 2015). Evergreen PFTs were also not considered, as there are no phenology modules related to these PFTs in the model. The procedure is similar to that described in detail in MacBean et al. (2015) and therefore only briefly recalled here. A simple linear relationship between the modeled FAPAR and MODIS-NDVI observations is assumed, based on studies such as Knyazikhin et al. (1998). Given that considerable discrepancies exist between so-called "high-level" satellite products such as LAI or FAPAR when considering their magnitude (D'Odorico et al., 2014), we thus only use the temporal information in the NDVI observations and normalized both the model FAPAR output and the NDVI observations to their 5th and 95th percentiles (following Bacour et al., 2015, and MacBean et al., 2015). Note that assimilating raw FAPAR data with the ORCHIDEE model led to the degradation of the NEE with the estimation of spurious parameter values (Bacour et al., 2015). The model was run for 15 randomly selected grid cells for each of the four PFTs using the ERA-Interim meteorological forcing. Only grid cells that included vegetation fraction of greater than $60 \%$ for the PFT optimized were considered. We selected a set of grid points instead of the whole grid to substantially decrease the computing time; but the remaining points are used for the evaluation of the optimized model. The 15 sites for each PFT were included in one optimization for each PFT following a multi-site approach, in which all observations are used simultaneously to optimize the model parameters. The optimized parameters are described in Table 1 . They correspond to a scalar on the growing degree days (GDD) threshold for the start of the vegetation ( $\left.K_{\text {pheno,crit }}\right)$, a parameter controlling the use of carbohydrate reserve during the start of leaf growth $\left(K_{\mathrm{LAI}, \text { happy }}\right)$, a temperature threshold 


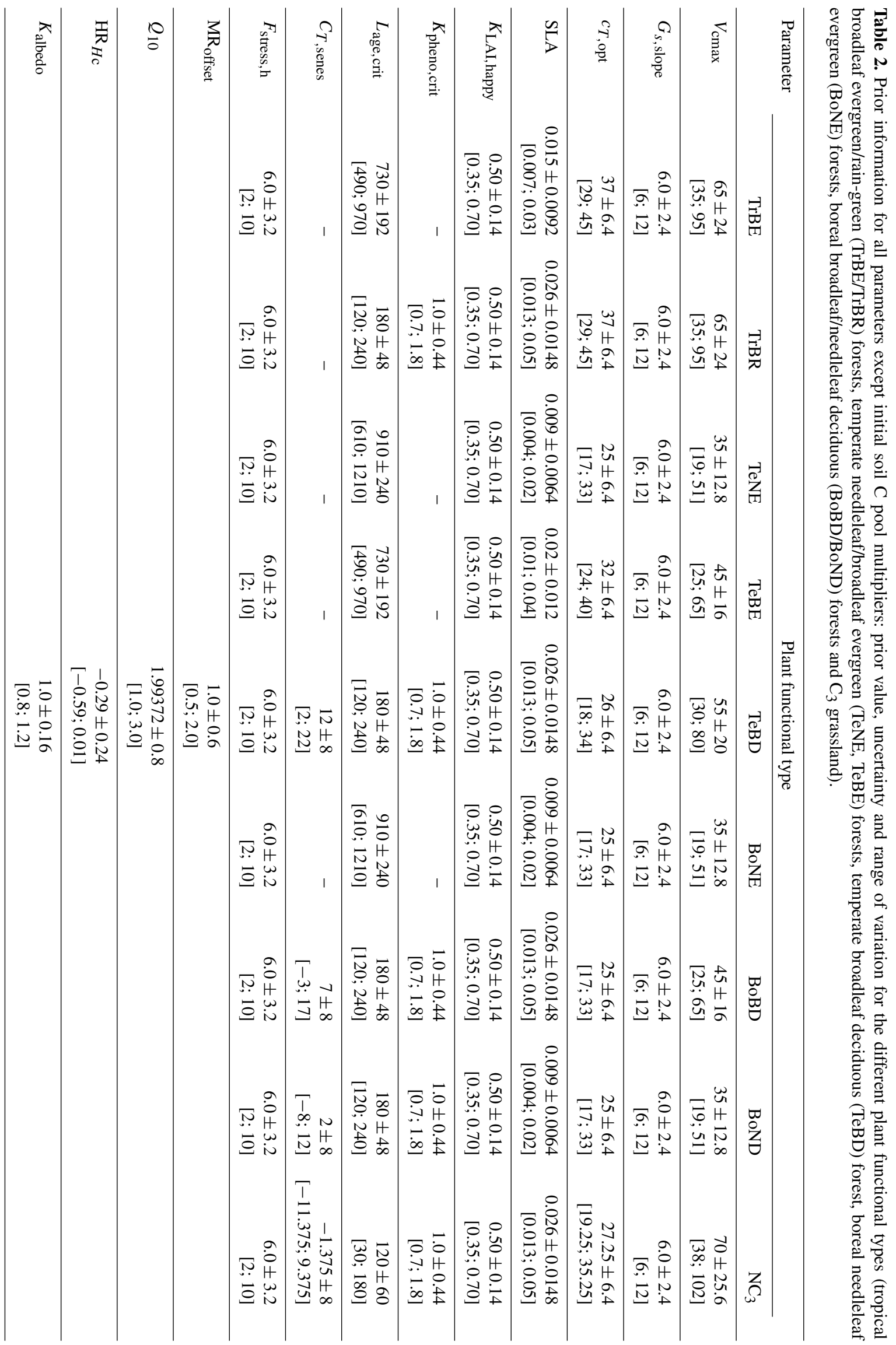


for the onset of leaf senescence $\left(\mathrm{CT}_{\text {senes }}\right)$ and the critical age for leaves $\left(L_{\text {agecrit }}\right)$.

Step 2 - assimilation of FLUXNET data: mean daily NEE and LE flux measurements for 78 sites, including up to 10 years worth of data for each site, are used to optimize a set of model parameters controlling the fast carbon and water processes (photosynthesis, respiration, phenology; see Table 1). The site selection and the choice of a daily time step are described in more details in Kuppel et al. (2014). These sites cover seven of the PFTs in ORCHIDEE (see Table 2). The posterior parameter values of the four phenology parameters derived in step 1, and their associated uncertainties, are input as prior information in step 2. For the additional parameters, the default ORCHIDEE values are used for the prior and the uncertainties are set as described in Sect. 2.3.3. A multi-site optimization is performed for each PFT independently as in step 1 . Global parameters, i.e., those that are not PFT-dependent, were optimized for each PFT and the mean across all PFTs was then calculated to define the prior parameter vector in step 3 of the assimilation with atmospheric $\mathrm{CO}_{2}$ data (at global scale). Such an approach was chosen to allow us to optimize all PFTs in parallel and therefore to simplify the assimilation process.

Step 3 - assimilation of atmospheric $\mathrm{CO}_{2}$ concentrations: we use monthly mean $\mathrm{CO}_{2}$ concentrations from 53 surface stations over 3 years (2002-2004) to provide a large-scale constraint to the land surface fluxes (i.e., to match the global $\mathrm{CO}_{2}$ growth rate, mean seasonal cycle and its latitudinal variation, as well as the spatial gradients between stations). We use the LMDz atmospheric transport model (see Sect. 2.3.2) to assimilate these observations. The set of parameters optimized in step 2 are included in step 3, except for the albedo scaling parameter $\left(K_{\text {albedo,veg }}\right)$, as the net carbon fluxes are only weakly sensitive to that parameter. We used the posterior parameter distributions from step 2 (parameter optimal values and associated uncertainties) as prior information for step 3 , and expanded the parameter vector to include the $30 K_{\text {soilC }}$ parameters that scale the initial soil carbon pools for large "spatially coherent regions" (see Sect. 2.1.2 and Fig. A2). The air-sea fluxes and fossil fuel and biomass burning emissions are also accounted for (but not optimized) in this final step, in order to close the global carbon budget within the atmospheric transport model (see Sect. 2.5).

\subsubsection{Optimization procedure (for all steps)}

In each step the statistically optimal parameter values are derived with an optimization procedure following the principle of the 4-D variational assimilation systems (developed for numerical weather prediction), using a tangent linear operator (and finite differences for a few parameters, Bacour et al., 2015). Assuming that the errors associated with the parameters, the observations and the model outputs follow Gaussian distributions, the optimal parameter set corresponds to the minimum of a cost function, $J(x)$, that measures the mismatch between (i) the observations ( $\boldsymbol{y}$ ) and the corresponding model outputs, $H(\boldsymbol{x})$, (where $H$ is the model operator), and (ii) the a priori $\left(\boldsymbol{x}_{b}\right)$ and optimized parameters $(\boldsymbol{x})$, weighted by their error covariance matrices (Tarantola, 1987; chap. 4):

$$
\begin{aligned}
J(x)= & \frac{1}{2}\left[(H(x)-y)^{T} \mathbf{R}^{-1}(H(x)-y)\right. \\
& \left.+\left(\boldsymbol{x}-\boldsymbol{x}_{b}\right)^{T} \mathbf{B}^{-1}\left(\boldsymbol{x}-\boldsymbol{x}_{b}\right)\right] .
\end{aligned}
$$

$\mathbf{R}$ represents the error variance/covariance matrix associated with the observations and $\mathbf{B}$ the parameter prior error variance/covariance matrix. At each step a different cost function is defined with the observations and parameters related to that step (see Fig. 2). $\mathbf{R}$ includes the errors on the measurements, the model structure and the meteorological forcing. Model errors are rather difficult to assess and may be much larger than the measurement error itself. Therefore we chose to focus on the structural error and defined the variances in $\mathbf{R}$ as the mean squared difference between the prior model and the observations for both steps 1 and 2 (see Kuppel et al., 2013). For simplicity we assumed that the observation error covariances were independent between the different observations and therefore we kept $\mathbf{R}$ diagonal (off-diagonal terms set to zero), given the rapid decline of the model error autocorrelation beyond 1 day (Kuppel et al., 2013). For step 3 we used a different approach, given the large bias in the model a priori concentrations, and therefore followed the methodology of Peylin et al. (2005) based on the observed and modeled temporal concentration variability at each site. Overall, data uncertainties in the optimization procedure are between 0.1 and 0.45 for NDVI (step 1), around 3-6 $\mathrm{mg} \mathrm{C} \mathrm{m}^{-2} \mathrm{~d}^{-1}$ for daily NEE, and $15-30 \mathrm{Wm}^{-2}$ for daily LE (step 2) and between $0.1 \mathrm{ppm}$ at remote oceanic stations and $4 \mathrm{ppm}$ at continental sites (step 3).

The determination of the optimal parameter vector that minimizes $J(\boldsymbol{x})$ is performed by successive calls to a "gradient-descent" minimization algorithm L-BFGS-B (Byrd et al., 1995), which is specifically dedicated to solving large nonlinear optimization problems that are subject to simple bounds on the parameter values. In order to find the minimum of $J(x)$, the algorithm requires the gradient of $J(\boldsymbol{x})$ (Jacobian) with respect to the ORCHIDEE parameters. L-BFGS-B explores each parameter space simultaneously along the gradient of the cost function, and uses an approximation of the Hessian (second derivative) of $J(\boldsymbol{x})$, which is updated at each iteration, to define the size of the step at each iteration.

For steps 1 and 2, the model " $H$ " simply corresponds to the land surface model: $H=S$, with $S(\boldsymbol{x})$ representing the surface fluxes from the ORCHIDEE model using the parameter vector, $\boldsymbol{x}$. The gradients $\mathrm{d} J(\boldsymbol{x}) / \mathrm{d} \boldsymbol{x}$ are calculated from the tangent linear model of ORCHIDEE that was automatically generated by the numerical transformation of algorithms in Fortran (www.fastopt.de), except for two parameters linked 
to the model phenology for which the threshold functions prevent the use of a linear approximation. A finite difference approach was used for these parameters in order to define a mean derivative at any point; we also checked that no spurious oscillations occurred for these parameters during the minimization iterations.

For step 3, the model " $H$ " corresponds to the composition of the land surface model with the transport model: $H=T$ o $S$ (see Kaminski et al., 2002 for details), with $T$ representing the LMDz transport model. $T$ is a linear operator for a non-reactive species: $T(S(\boldsymbol{x}))=\mathbf{T} \times S(\boldsymbol{x})$, with $\mathbf{T}$ a matrix representation of the transport operator. It corresponds to the sensitivity of $\mathrm{CO}_{2}$ concentrations at each site and for each month to the daily surface flux of each model grid cell. It is then combined with the ORCHIDEE surface fluxes $(S(x))$ through a matrix multiplication to derive $H(\boldsymbol{x})$. T has been pre-calculated for all atmospheric stations in order to save computing time during the iterative optimization process (see Sect. 2.3.2). For simplicity we use monthly mean values for both the fluxes $S(\boldsymbol{x})$ and the transport sensitivities (T) in the computation of the gradients $\mathrm{d} J(\boldsymbol{x}) / \mathrm{d} \boldsymbol{x}$.

For improved minimization efficiency, the inversion is preconditioned (following Chevallier et al., 2005), which means that L-BFGS-B is fed with the control variable $\boldsymbol{x}^{\prime}=$ $\mathbf{B}^{-1 / 2}\left(\boldsymbol{x}-\boldsymbol{x}_{b}\right)$, rather than with $\boldsymbol{x}$, as this homogenizes the range of variation of the optimized parameters.

\subsubsection{Error estimation}

The posterior parameter error covariance matrix, $\mathbf{A}$, can be approximated to the inverse Hessian of the cost function, using the linearity assumption at the minimum of $J(x)$. It can be derived with the Jacobian of the model at the end of the minimization (i.e., the last iteration), $\mathbf{H}_{\infty}$, following Tarantola (1987):

$\mathbf{A}=\left[\mathbf{H}_{\infty}^{T} \times \mathbf{R}^{-1} \times \mathbf{H}_{\infty}+\mathbf{B}^{-1}\right]^{-1}$.

Note that for step 3, $\mathbf{H}_{\infty}=\mathbf{T} \times \mathbf{S}_{\infty}$, where $\mathbf{S}_{\infty}$ is the Jacobian of the ORCHIDEE model at the last iteration. The posterior parameter error covariance, $\mathbf{A}$, can then be propagated into the model state variable space (e.g., carbon fluxes and stocks), $\mathbf{A}_{\mathrm{var}}$, given the following matrix product (only used for the global fluxes in step 3):

$\mathbf{A}_{\text {var }}=\mathbf{S}_{\infty} \times \mathbf{A} \times \mathbf{S}_{\infty}^{T}$.

The square root of the diagonal elements of $\mathbf{A}_{\mathrm{var}}$ corresponds to the standard deviation, $\sigma$, of carbon fluxes/stocks for each grid cell. In order to evaluate the knowledge improvement brought by the assimilation, the uncertainty reduction between the prior $\left(\sigma_{\text {prior }}\right)$ and posterior $\left(\sigma_{\text {post }}\right)$ is determined as $1-\left(\sigma_{\text {post }} / \sigma_{\text {prior }}\right)$.

\subsubsection{Additional processing steps}

In order to analyze the fit to the atmospheric $\mathrm{CO}_{2}$ concentrations in terms of the trend and seasonal cycle, we decomposed the observed and modeled time series by fitting the monthly mean values with a function comprising a first-order polynomial term and four harmonics, and then filtered the residuals of that function in frequency space using a lowpass filter (cutoff frequency of 65 days), following Thoning et al. (1989). The polynomial term defines the trend while the seasonal cycle corresponds to the harmonics plus the filtered residuals. The amplitude of the seasonal cycle is then calculated as the difference between the monthly mean maximum and minimum for year 2003 (middle year of the optimization period). Finally, we define the carbon uptake period (CUP) as the sum of the days when the values of the seasonal cycle extracted from the $\mathrm{CO}_{2}$ concentration time series are negative (a negative convention being for $\mathrm{CO}_{2}$ removed from the atmosphere).

\subsection{Prescribed emissions of carbon fluxes}

In this section we describe the other components of the carbon cycle (apart from the surface $\mathrm{C}$ exchange with terrestrial vegetation) that are imposed in step 3 of the optimization process as fixed fluxes.

\subsubsection{Ocean fluxes}

The ocean contributes to an uptake of about one-quarter to one-third of the anthropogenic emissions with significant year-to-year variations (Sabine et al., 2004). For this version of the ORCHIDAS, we developed a statistical model to estimate the spatial and temporal variations (monthly) of the ocean surface $\mathrm{CO}_{2}$ partial pressure $\left(p \mathrm{CO}_{2}^{\mathrm{SW}}\right)$, and from that the air-sea $\mathrm{CO}_{2}$ fluxes, using satellite and in situ ocean measurements and model outputs. The air-sea $\mathrm{CO}_{2}$ fluxes are primarily controlled by the ocean biogeochemistry, the horizontal transport and the vertical mixing in the ocean and the atmospheric forcing $\left(\mathrm{CO}_{2}\right.$ partial pressure at the interface to the water $\left(p \mathrm{CO}_{2}^{\mathrm{ATM}}\right)$ and wind); they can be defined from the following equation:

$F_{\mathrm{CO}_{2}}=K_{\mathrm{ex}} \times\left(p \mathrm{CO}_{2}^{\mathrm{SW}}-p \mathrm{CO}_{2}^{\mathrm{ATM}}\right)$,

where $K_{\text {ex }}$ stands for the exchange coefficient and $F_{\mathrm{CO}_{2}}$ the $\mathrm{CO}_{2}$ flux from the sea surface water to the atmosphere.

The computation of $p \mathrm{CO}_{2}^{\mathrm{SW}}$ is performed using feedforward artificial neural networks, i.e., a multiLayer perceptron (MLP; Rosenblatt, 1958) that maps a set of spatiotemporal variables (input) onto observed $p \mathrm{CO}_{2}^{\mathrm{SW}}$ data. We use a two-step approach: the first step to derive a monthly mean $p \mathrm{CO}_{2}^{\mathrm{SW}}$ climatology and the second step to correct for the year-to-year variations. The $p \mathrm{CO}_{2}^{\mathrm{SW}}$ observations come from the global surface $p \mathrm{CO}_{2}$ (Lamont-Doherty Earth Observatory, LDEO) Database (Takahashi et al., 2009). The inputs 
are a series of variables connected to the spatial and temporal evolution of $p \mathrm{CO}_{2}^{\mathrm{SW}}$ : (i) sea surface temperature (SST), sea surface salinity (SSS) and mixed layer depth (MLD) as a proxy of the physical processes (these fields come from a reanalysis of the Nucleus for European Modelling of the Ocean (NEMO) ocean model (Madec et al., 1998) with the assimilation of several satellite observations), (ii) chlorophyll content from SeaWiFS (Sea-viewing Wide Field-of-view Sensor), as a proxy of the biogeochemistry (CHL), (iii) spatial and temporal coordinates (LAT, LON and MONTH) and the $p \mathrm{CO}_{2}^{\mathrm{SW}}$ at previous time step (recursive approach), i.e.,

$$
\begin{aligned}
\left\{p \mathrm{CO}_{2}^{\mathrm{SW}}\right\}_{\mathrm{m}}= & \operatorname{MLP}\left(\{\mathrm{SST}, \mathrm{SSS}, \mathrm{MLD}, \mathrm{CHL}\}_{(\mathrm{m}-2, \mathrm{~m}-1, \mathrm{~m})}\right. \\
& \left.\left\{p \mathrm{CO}_{2}^{\mathrm{SW}}\right\}_{(\mathrm{m}-2, \mathrm{~m}-1)}, \mathrm{LAT}, \mathrm{LON}\right)
\end{aligned}
$$

where $\mathrm{m}$ is the monthly index. The available data (20685 points) is divided into two parts: $75 \%$ is used for the learning phase of the ANN and $25 \%$ for the validation phase. The overall performance of the neural network for extrapolating the spatial and seasonal distribution of $p \mathrm{CO}_{2}^{\mathrm{SW}}$ is relatively good, with a spatiotemporal correlation coefficient between the estimated $p \mathrm{CO}_{2}^{\mathrm{SW}}$ and the independent observations of 0.80 .

$p \mathrm{CO}_{2}^{\mathrm{ATM}}$ at the surface are taken from a global simulation of atmospheric $\mathrm{CO}_{2}$ concentrations with optimized fluxes (Chevallier et al., 2010). $K_{\mathrm{ex}}$ is defined as the product of $k$, the gas transfer velocity, taken from the Wanninkhof (1992) formulation using winds from ERA-Interim, and $s$, the solubility of $\mathrm{CO}_{2}$, taken from the Weiss formulation (Weiss, 1974). The system is further described in Rödenbeck et al. (2015). The global ocean sink is around $1.60 \mathrm{PgC} \mathrm{yr}^{-1}$ for the period 2002-2004 used in step 3. It is within the uncertainty range of the Global Carbon Project (GCP) estimates (Le Quéré et al., 2015) if we account for the pre-industrial ocean outgassing flux included in our "delta $\mathrm{pCO}_{2}$ " approach. Its temporal evolution is depicted in Fig. A1.

\subsubsection{Global fossil fuel and cement $\mathrm{CO}_{2}$ emissions}

We have used a recently developed $\mathrm{CO}_{2}$ fossil fuel and cement emission product (see http://www.carbones.eu/ wcmqs/) that covers the period 1980 to 2009 at the spatial resolution of $1^{\circ} \times 1^{\circ}$ and hourly resolution. It is based on EDGAR v4.2 spatially distributed annual emissions (Olivier et al., 2012) and time profiles developed by the University of Stuttgart (http://carbones.ier.uni-stuttgart.de/ wms/impressum.html). It was assumed that EDGAR delivers the most up-to-date spatially distributed and sector specific emissions, based on national emission statistics. The IER (Institut für Energiewirtschaft und Rationelle Energieanwendung) further applied country and sector specific time profiles, taking into account monthly, daily, and hourly variations depending on the sector. The derivation of the time profiles relies on different data sets (e.g., Eurostat; ENSTO-E, https://www.entsoe.eu/about-entso-e/Pages/ default.aspx; UN monthly bulletin) as well as correlations between recorded emissions and climate variables. Currently, the temporal profiles are derived mostly from data sets over Europe that were extrapolated using information on climate zone, average monthly temperature for the seasonal cycles and similarity in socio-economic parameters like population and gross domestic product (GDP). The annual mean emission for the period 2002-2004 is 7.14 $\mathrm{PgC} \mathrm{yr}^{-1}$.

\subsubsection{Fire emissions}

Fire emissions data from the Global Fire Data (GFEDv3; https://daac.ornl.gov/VEGETATION/guides/global_fire_ emissions_v3.1.html) are prescribed in the ORCHIDAS (except during the model spin-up). The GFEDv3 data are broken-down into six sectors (deforestation, peat fires, savanna fires, agriculture, forest fires, and woodland) that are further grouped into three main types. We generated fluxes of $\mathrm{CO}_{2}$ relevant for typical "burning-regrowth" processes, as detailed in Appendix A2. The first type corresponds to deforestation and peat fires with carbon permanently lost to the atmosphere, the second to agriculture and savannah fires, which are assumed to be compensated by a sink during the regrowth period (i.e., with zero annual net emission for each pixel), and the third to woodland and burnt forests, which are assumed to be at steady state for a given region (10 sub-continental-scale regions) over the period covered by GFEDv2 (i.e., regrowth of nearby forest compensates for the burned forest derived in GFED). The sum of these three components leads to the global flux, with a gross emission around $2.1 \mathrm{PgC} \mathrm{yr}^{-1}$ and a net emission after regrowth of only $1.1 \mathrm{PgC} \mathrm{yr}^{-1}$ (Fig. A2 in the Appendix) that is prescribed to the ORCHIDAS over the period 2002-2004.

\section{Results}

\subsection{Model fit to the data}

\subsubsection{Step 1: assimilation of MODIS NDVI data}

The optimization in step 1 resulted in an improved fit to the MODIS NDVI observations for the four PFTs considered (TeBD, BoND, BoBD, $\mathrm{NC}_{3}$; see Sect. 2.4) as seen in Fig. 4, which shows the mean seasonal cycle across the 2000-2008 period for all sites for each PFT. The most prominent change after the optimization was a substantially shorter growing season for all PFTs due to an earlier start of leaf senescence. This was caused by both a lower critical leaf age $\left(L_{\text {agecrit }}\right)$ and a higher temperature threshold for senescence $\left(\mathrm{CT}_{\text {senes }}\right)$ (see Fig. 9). The impact on the start of leaf growth was less dramatic but important nonetheless, with a shift to a later start of leaf growth as a result of an increase in the $K_{\text {pheno,crit }}$ parameter, which acts as a scalar on the threshold of GDD used to trigger leaf onset (see Appendix A in MacBean et al., 2015). Overall, a mean reduction in root mean square er- 

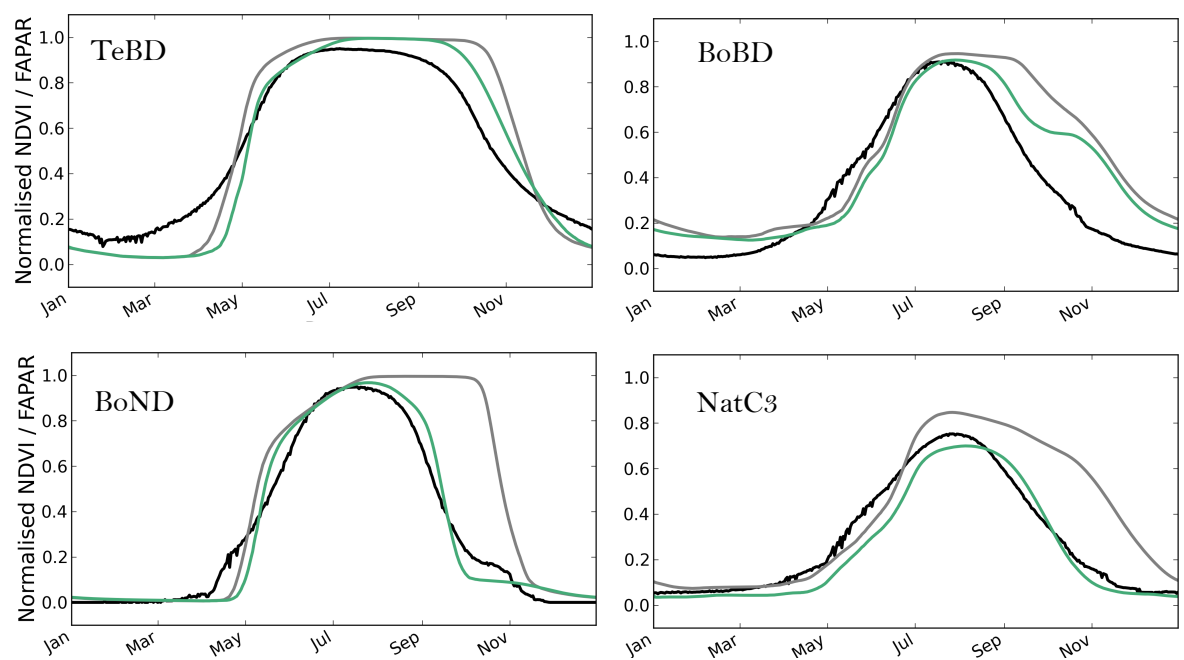

Figure 4. Mean seasonal cycle (2000-2008) of the normalized modeled FAPAR before and after optimization, compared to that of the MODIS NDVI data, for the temperate and boreal deciduous PFTs (TeBD, BoBD, BoND and NatC3). Black= MODIS NDVI data; gray $=$ prior simulation (default ORCHIDEE parameters); green $=$ posterior multi-site optimization.

ror (RMSE) of 23, 17, 58 and $19 \%$ was achieved for TeBD, $\mathrm{BoBD}, \mathrm{BoND}$ trees and $\mathrm{NC}_{3}$ grasses, respectively, with the greatest improvement for BoND trees. The mean correlation between the normalized MODIS-NDVI and modeled FAPAR time series over the 2000-2008 period increased for TeBD and BoND trees and $\mathrm{NC}_{3}$ grasses (prior and posterior of 0.9 to $0.93,0.42$ to 0.91 and 0.6 to 0.66 , respectively). The prior correlation of 0.55 remained similar after the assimilation for BoBD trees.

Following the improvement at the sites selected for the optimization, we evaluated the impact for each PFT at the global scale using the global median correlation between the MODIS-NDVI and the model FAPAR time series (from all pixels where the fraction of a given PFT is above $60 \%$; see Maignan et al., 2011). The global correlation increased for BoND trees and $\mathrm{NC}_{3}$ grasses from 0.36 to 0.91 and 0.53 to 0.59 (prior to posterior), respectively. It remains stable for BoBD (0.54) or slightly increased for TeBD (0.88 to 0.89).

\subsubsection{Step 2: assimilation of FLUXNET data}

The optimization in step 2 brings an improvement to the simulated NEE and LE for all seven PFTs considered, with Fig. 5 showing the corresponding PFT-averaged mean NEE seasonal cycles (mean across all sites/years). NEE is overestimated by the prior model for all PFTs on average. This is partly due to the model spin-up procedure, which brings each simulated site to a near equilibrium state with a mean NEE close to zero (i.e., no net carbon sink, see Sect. 2.1.1). This bias is significantly corrected by the optimization to match the observed carbon uptake at most sites, notably via the scaling of the initial soil carbon pool content at each site (parameters $K_{\text {soilC,site; }}$ Table 1 ), which thus significantly reduces

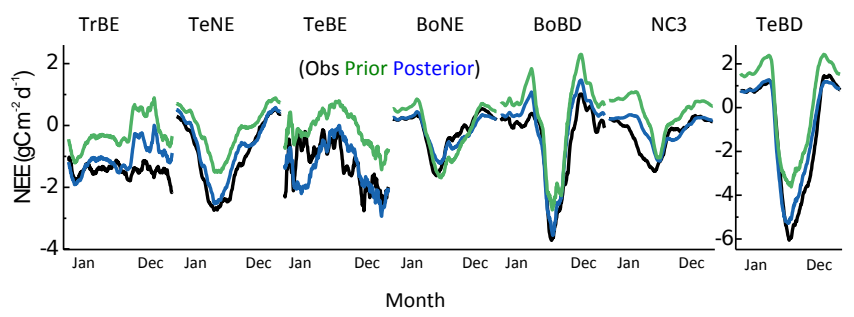

Figure 5. Mean seasonal cycle of the net ecosystem exchange (NEE) for the different plant functional type optimized in step 2 of the assimilation. The mean across all sites for a given PFT is provided for the observations (black), the posterior of step 1 (green) and the posterior of step 2 (blue).

the ecosystem respiration (Kuppel et al., 2014). Overall, the largest reductions of model-data RMSE are found in temperate forests (TeNE: temperate needleleaf, TeBE: temperate broadleaf evergreen and TeBD: temperate broadleaf deciduous), where the RMSE decreased by more than $25 \%$ compared with the prior model. The improvements are less significant for the other PFTs, with RMSE reductions between 10 and $18 \%$.

In addition, the optimization increases the NEE seasonal amplitude in temperate evergreen (TeNE and TeBE) forests and temperate broadleaf deciduous (TeBD) forests, and reduces the amplitude for boreal needleleaf evergreen (BoNE) forest and natural $\mathrm{C}_{3}$ grasses $\left(\mathrm{NC}_{3}\right)$, in agreement with the observations (except for BoNE where the amplitude decrease is too large). Despite the better model-data agreement for evergreen broadleaf forests (TrBE: tropical broadleaf evergreen and TeBE), the optimized model still fails to catch some seasonal features such as a persistent carbon uptake (i.e., nega- 

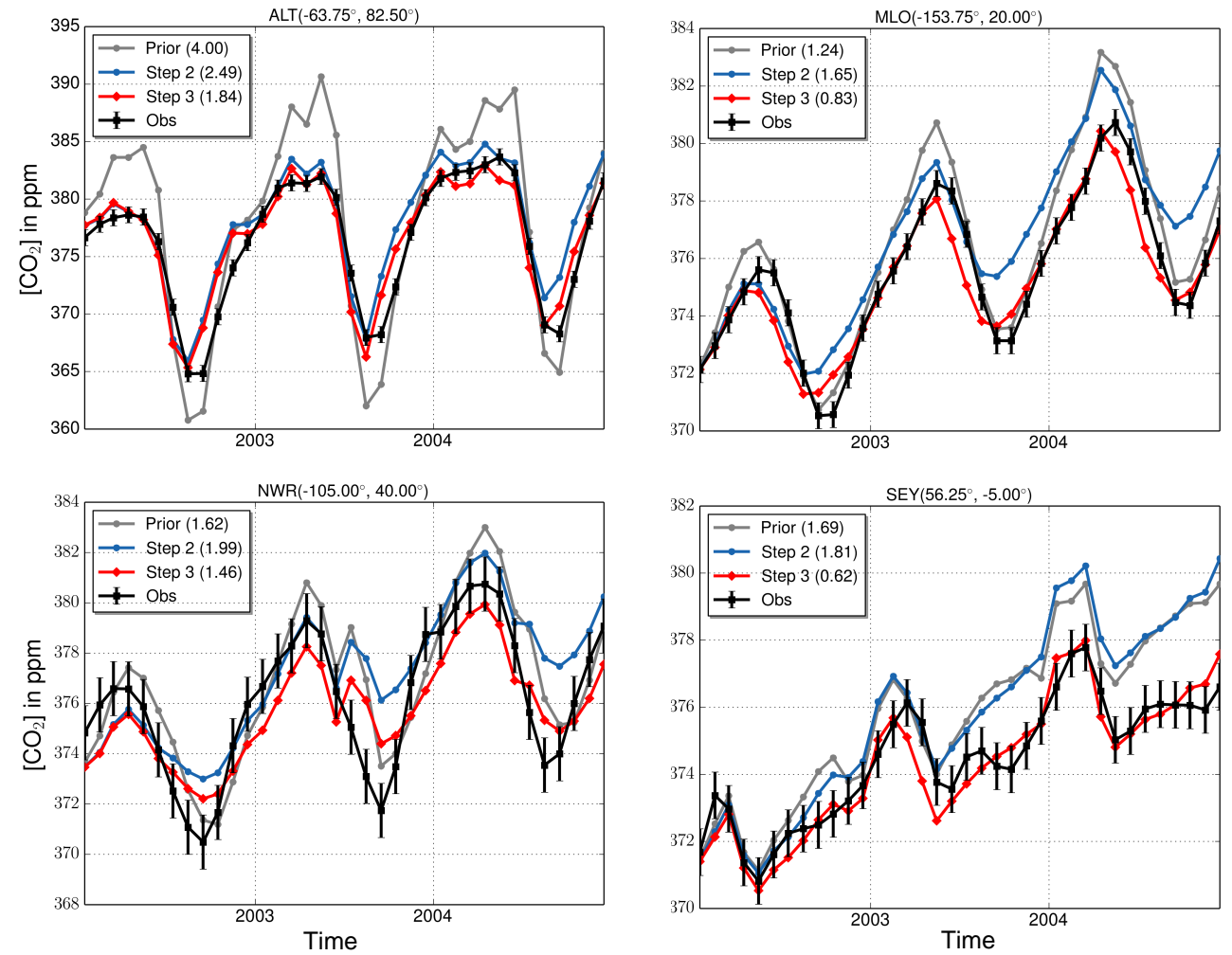

Figure 6. Monthly mean atmospheric $\mathrm{CO}_{2}$ concentrations after step 3 of the optimization, for several stations over the period 2002-2004 of the optimization. The observations (black), the prior model (gray) and the posterior model after step 2 (blue) and step 3 (red) are displayed. Numbers in parenthesis correspond to RMSEs.

tive NEE) in the dry season for the tropical regions (TrBE) and nearly null carbon exchange in the first months of the year for temperate regions (TeBE). These results are discussed further in Kuppel et al. (2014), who used a similar optimization setup with a slightly different parameter set see Sect. 2.3.3. Similar improvements, although of smaller amplitude, occur for the latent heat fluxes (not shown).

\subsubsection{Step 3: assimilation of atmospheric $\mathrm{CO}_{2}$ data}

The final optimization step with the atmospheric $\mathrm{CO}_{2}$ concentrations provides a large improvement of the fit to the observed concentrations at most stations. The cost function $J$ was reduced through the minimization by a factor of 5.7 within 37 iterations.

Figure 6 illustrates the simulated concentrations for four stations (representative of different conditions), over the assimilation period, with the standard prior parameter vector (used in step 1), the posterior vector from step 2 (used as prior in step 3) and the posterior vector from this last step. The improvement in the fit to the observations can be quantified with the reduction in RMSE (from the prior to the posterior of step 3) - the largest reduction is at the South Pole station $(73 \%)$ and is on average around $25 \%$ across all sites. Note that for a few stations the fit is slightly degraded (up to $10 \%$ ) except for one Pacific site (regular ship measurements around the Equator, POCNO0) for which there is a $40 \%$ degradation, possibly due to small biases in the simulation of the ITCZ (Intertropical Convergence Zone) position in LMDz. When calculated with respect to the standard prior (used in step 1) the RMSE decrease is slightly larger on average, especially for the northern mid-to-high latitude stations. For these stations the optimization performed in step 2 with FLUXNET data led to a significant improvement of the mean seasonal cycle amplitude of the atmospheric $\mathrm{CO}_{2}$ data, as discussed in Kuppel et al. (2014).

We then investigated the fit to the observed $\mathrm{CO}_{2}$ concentrations in terms of the mean seasonal cycle and trend (see Sect. 2.4.4). With only 3 years of data the mean trend is more difficult to define as it varies between stations; however, the optimization in step 3 increases the net land carbon sink in order to match the observed trend at most stations (as expected). If we take the Mauna Loa and South Pole stations that are representative of an integration of the fluxes at hemispheric scales, the prior $\mathrm{CO}_{2}$ trend of 2.8 and $2.9 \mathrm{ppm} \mathrm{yr}^{-1}$, respectively, is reduced to 2.1 and $2.2 \mathrm{ppm} \mathrm{yr}^{-1}$ close to the observations ( $2.1 \mathrm{ppm} \mathrm{yr}^{-1}$ for both). The left panel of Fig. 7 illustrates changes in the amplitude of the simulated seasonal cycle at each station (see definition in Sect. 2.4.4). The values correspond to relative changes between the prior (of step 3) 
(a) Seasonal amplitude: relative changes

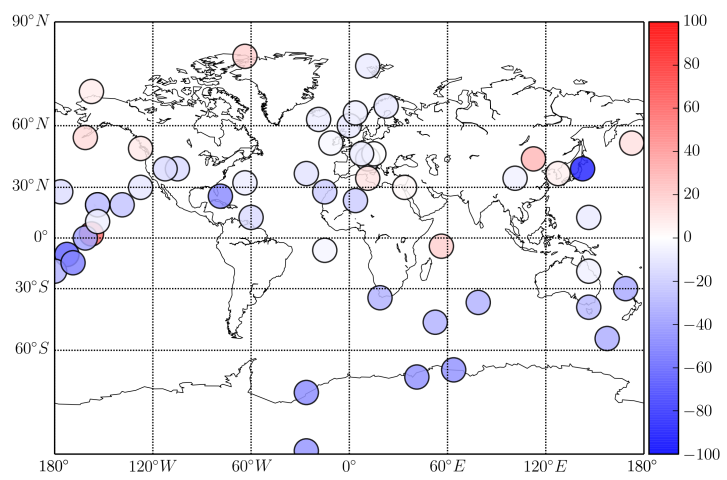

(b) Length of CUP: relative changes

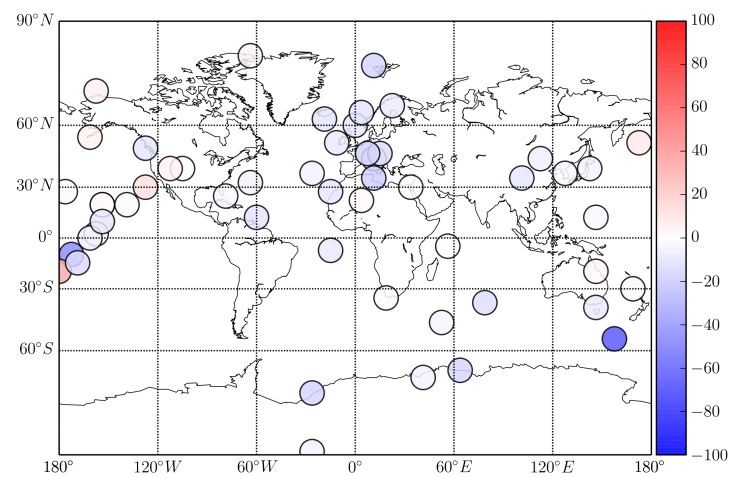

Figure 7. Changes in the mean seasonal cycle of the atmospheric $\mathrm{CO}_{2}$ concentrations after step 3 of the optimization at all atmospheric stations. Left: relative changes (in percentage) between the prior of step 3 and posterior absolute model-data differences for the amplitude of the seasonal cycle. Right: same metric but for the length of the carbon uptake period (CUP), measured as the sum of the days when the de-trended concentrations are negative (see text).

and posterior of the absolute difference between observed and modeled amplitude $\left(\left[\left|\Delta A_{\text {post }}\right|-\left|\Delta A_{\text {prior }}\right|\right] /\left|\Delta A_{\text {prior }}\right|\right)$. They reveal an improvement in the seasonal cycle amplitude at nearly all stations of the Southern Hemisphere $(\approx 40 \%$ improvement) and at the majority of the Northern Hemisphere stations $(\approx 15 \%)$. A few stations in northern East Asia (3) and northwestern America (4) show a small degradation of the amplitude $(\approx 15 \%)$. The right panel of Fig. 7 displays the changes of the CUP (see Sect. 2.4.4) expressed in terms of relative changes between prior and posterior of the absolute values of model-data differences, as it is for the amplitude. Most stations reveal an improvement of the CUP of around $20 \%$, which is slightly lower than the improvement for the seasonal cycle amplitude.

Finally, we verified that the improvement is valid not only at the optimization sites but also at independent atmospheric $\mathrm{CO}_{2}$ stations (see Sect. 2.2.3). On average the mean RMSE for the 24 additional sites is $10.5 \mathrm{ppm}$ for the prior of step 1 (prior of ORCHIDEE), $2.8 \mathrm{ppm}$ for the prior or step 3 (i.e., posterior of step 2) and $2.1 \mathrm{ppm}$ for the posterior of step 3 . The corresponding values for the 53 sites used for the optimization are 10.5, 2.45 and $1.8 \mathrm{ppm}$, respectively. The error reduction during step 3 is thus similar for both the assimilated and the validation data sets, further confirming that the optimization provides a global improvement of the simulated carbon fluxes.

\subsection{Consistency of the stepwise optimization}

The main issue with a stepwise data assimilation system (vs. a simultaneous approach) concerns the potential degradation of the model-data fit for the different data streams that are assimilated in previous steps. We noted that $\mathrm{CO}_{2}$ concentrations were already improved when NDVI and FLUXNET data are assimilated (see Sect. 3.1.3), but we need to check if the final parameter set from step 3 leads to a degradation of the fit to MODIS-NDVI (step 1) and to FLUXNET (step 2) data compared to the fit achieved during the respective steps and, in the case of a significant degradation, if we still have an improvement for these data streams compared to the initial a priori fit.

Figure 8 summarizes the performance of the model data fit for MODIS-NDVI and FLUXNET-NEE data streams for the prior and posterior of each step by evaluating the median RMSE between the model and the observations across all sites. The values are calculated for each PFT separately. In this section, we keep in mind the fact that we do not optimize the same PFTs with FLUXNET data and with MODISNDVI.

\subsubsection{Consistency for MODIS-NDVI}

First, we notice again the significant RMSE reduction between the prior and step 1, as discussed in Sect. 3.1. The fit to MODIS-NDVI (normalized data) for steps 2 and 3 shows only a significant degradation (increased RMSE) for temperate broadleaf deciduous (TeBD) forest, which decreases the improvement achieved in step 1 (compared to the prior) by a factor of 2. A marginal degradation for natural $\mathrm{C}_{3}$ $\left(\mathrm{NC}_{3}\right)$ grassland is obtained after step 3: the RMSE increases slightly from 0.24 to 0.26 , but is still lower than the prior value of 0.3 . There is no degradation for boreal needleleaf deciduous (BoND) trees, but a surprising small decrease of the RMSE (i.e., improvement in the model-data fit) for boreal broadleaf deciduous forests (BoBD; from 0.26 to 0.23 ). In this latter case, the use of additional parameters in steps 2 and 3 (see Sect. 2.4) allows for further improvement of the fit between the normalized FAPAR and NDVI time series. On average the degradation of the fit to NDVI is thus very limited in steps 2 and 3, and in no case is the RMSE worse than the prior. 

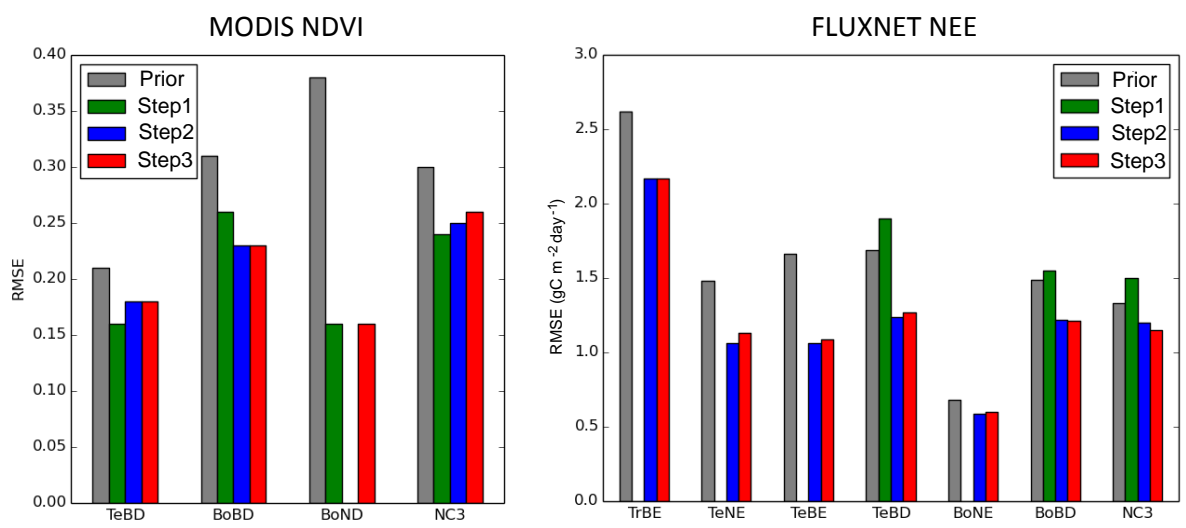

Figure 8. RMSE between model outputs and observations for two types of observations: MODIS-NDVI on the left and FluxNet-NEE on the right, for different plant functional types (PFT: TrBE, TeNE, TeBE, TeBD, BoBD, BoND, $\mathrm{NC}_{3}$ ) and for the prior model simulation and the posterior of each step of the assimilation framework. Missing bars correspond to the fact that no data were available to constrain a given PFT.

\subsubsection{Consistency for FLUXNET data}

Figure 8 again reveals the significant reduction of the RMSEs for NEE in step 2 compared to the standard prior or to the posterior of step 1 for most PFTs, except BoNE. We see only small degradations (increases) in RMSE between steps 2 and 3 for TeNE forests (from 1.06 to $1.13 \mathrm{~g} \mathrm{C} \mathrm{m}^{2} \mathrm{~d}^{-1}$ ), TeBE forests (from 1.06 to $1.09 \mathrm{~g} \mathrm{C} \mathrm{m}^{2} \mathrm{~d}^{-1}$ ), TeBD forests (from 1.06 to $1.13 \mathrm{~g} \mathrm{C} \mathrm{m}^{2} \mathrm{~d}^{-1}$ ) and BoNE forests (from 0.59 to $\left.0.60 \mathrm{~g} \mathrm{C} \mathrm{m}^{2} \mathrm{~d}^{-1}\right)$. An interesting feature to notice is that the NEE RMSE increases from the prior to the posterior of step 1 (i.e., before NEE has been used in the optimization in step 2). Using remote sensing products of vegetation activity or "greenness" (e.g., NDVI) to calibrate the phenology of ORCHIDEE thus does not always improve the simulated NEE, as they only provide a strong constraint on the timing of the leaf phenology (and thus indirectly the gross primary production, GPP) and a weak constraint on the maximum GPP but no constraint on the respiration fluxes. These reasons were discussed in Bacour et al. (2015), who used the same LSM and assimilation system. Overall, the reduction of the improvement of the model data fit to the NEE (step 3 vs. step 2) is marginal (limited to a few percent), thus further suggesting the consistency of our stepwise approach. Similar results are also obtained for the LE flux (not shown).

\subsection{Estimated parameter values}

We now discuss the parameter values, focusing on the changes obtained though the successive steps. Figure 9 presents the prior and posterior values for each parameter together with their associated uncertainties (estimated through Eq. 2) and the allowed range of variation. Note that nine parameters are PFT dependent while four are global (non PFT dependent). For the global non-PFT-dependent parameters included in the step 2 optimization, we took the mean value and error variance (see Sect. 2.4) as the prior for step 3. Note finally that the parameters linked to the initial soil carbon pools $\left(K_{\text {soilC,site }}, K_{\text {soilC,reg }}\right)$ are not shown in Fig. 9 as they are too numerous (though see Fig. A2 for the regional values).

If we first consider the phenology parameters optimized in step $1\left(K_{\mathrm{LAI}, \text { happy }}, K_{\text {pheno,crit }}, L_{\text {age_crit }}, C_{T \text {,senes }}\right.$; see Table 1), we see that for most PFTs they do not change significantly between steps 1 and 3, although they differ significantly from the prior. There are few exceptions, including $K_{\text {pheno,crit }}$ (the threshold for the start of the growing season) for boreal needleleaf deciduous forests and $K_{\mathrm{LAI} \text {,happy }}$ (level of carbohydrate use) for TeBD and BoBD. Note that a few phenology parameters hit one of the physical bounds, which may indicate model structural errors or model parameter equifinality. For most phenology parameters, the uncertainties are strongly reduced during their first optimization (step 1), except for a few cases like $C_{T \text {,senes }}$ for $\mathrm{C}_{3}$ grassland. Note finally that a more in depth spatiotemporal validation demonstrated the generality of the optimized phenology parameters across multiple sites (for further details see MacBean et al., 2015).

For the photosynthesis parameters ( $V_{\mathrm{cmax}}, G_{s, \text { slope }}, c_{T, \mathrm{opt}}$, SLA, $f_{\text {stress }}$; see Table 1$)$, we find a similar result with small changes between steps 2 and 3, but still a significant departure from the prior values. Most parameters are well constrained by the inversion, with posterior uncertainties that are greatly reduced compared to the prior, except for TrBR forest and BoND forest for which there is nearly no constraint on $G_{s, \text { slope }}$ and $f_{\text {stress }}$ (see Table 1).

The non-PFT-dependent respiration-related parameters $\left(\mathrm{HR}_{H, \mathrm{c}}, Q_{10}, \mathrm{MR}_{b}\right)$ mostly change in step 2 and only slightly in step 3 (with an additional reduction of the error) in order to fit the large-scale constraint provided by the atmospheric observations. The values of the scalar of the initial soil carbon pools size for the FLUXNET site optimizations $\left(K_{\text {soilC,site }}\right.$, one parameter per site, not shown) were largely reduced on 

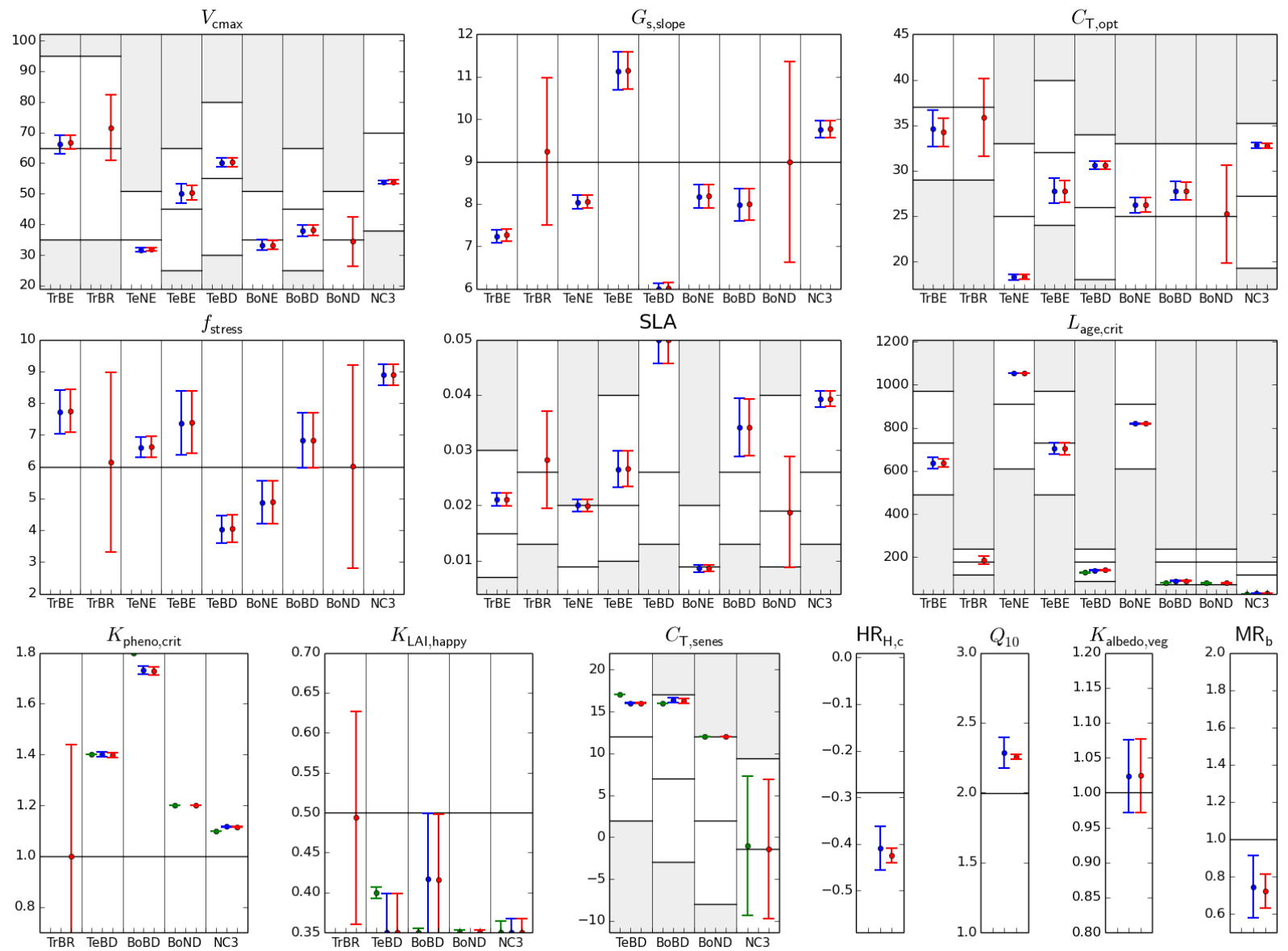

Figure 9. Prior and posterior parameter values and uncertainties for a set of optimized parameters (nine PFT dependent and four non-PFT dependent). The prior value corresponds to the horizontal black line and the physical allowed range of variation to the " $y$ " range (i.e., the white zone). For PFT-dependent parameters, there are nine sub-plots corresponding to PFTs that were optimized (except for $K_{\text {pheno,crit }}$ with only five PFTs). For each parameter, there are three estimated values for the three successive steps: step 1: assimilation of MODIS-NDVI data (green symbol); step 2: adding FLUXNET data (blue symbol); step 3: adding atmospheric $\mathrm{CO}_{2}$ data (red symbol). The parameter values are depicted with the symbols and the estimated uncertainties with the vertical line $( \pm \sigma)$.

average, in order to decrease the heterotrophic respiration (see Kuppel et al., 2014 for additional discussion). In step 3 the same scalars that were defined for an ensemble of large regions $\left(K_{\text {soilc,reg }}\right)$ have decreased in the Southern Hemisphere (less than 10\%; see Fig. A2 in Appendix A3) and slightly increased in the Northern Hemisphere (around $1 \%$ ), to achieve a better match to the atmospheric $\mathrm{CO}_{2}$ growth rate and north-south gradient. Importantly, we notice that for step 3, the fit to the atmospheric $\mathrm{CO}_{2}$ concentrations (especially to the trend) is achieved mainly by small changes in $K_{\text {soilC,reg }}$ and in few other respiration-related parameters. Note finally that the parameter controlling the albedo $\left(K_{\text {albedo,veg }}\right)$, modified with the FLUXNET observations only (see Sect. 2.4), is not well constrained by the optimization (only a small reduction in uncertainty). Overall, most parameters appear to be well constrained when first optimized, with only small changes in the following steps. This suggests that the targeting of different parameter subspaces in the various optimization steps was well chosen.

\subsection{Estimated carbon fluxes and uncertainties}

The main objective of a carbon cycle data assimilation procedure is to improve the simulated land surface net and gross carbon fluxes as well as the simulated carbon stocks for both present and future conditions. Given the focus of the paper, i.e., to describe the potential of a stepwise global carbon cycle data assimilation system, we only discuss a few largescale features of the optimized annual net and gross carbon fluxes, as well as one of the carbon stock variables (forest aboveground biomass). We thus do not discuss the interannual flux variability. 

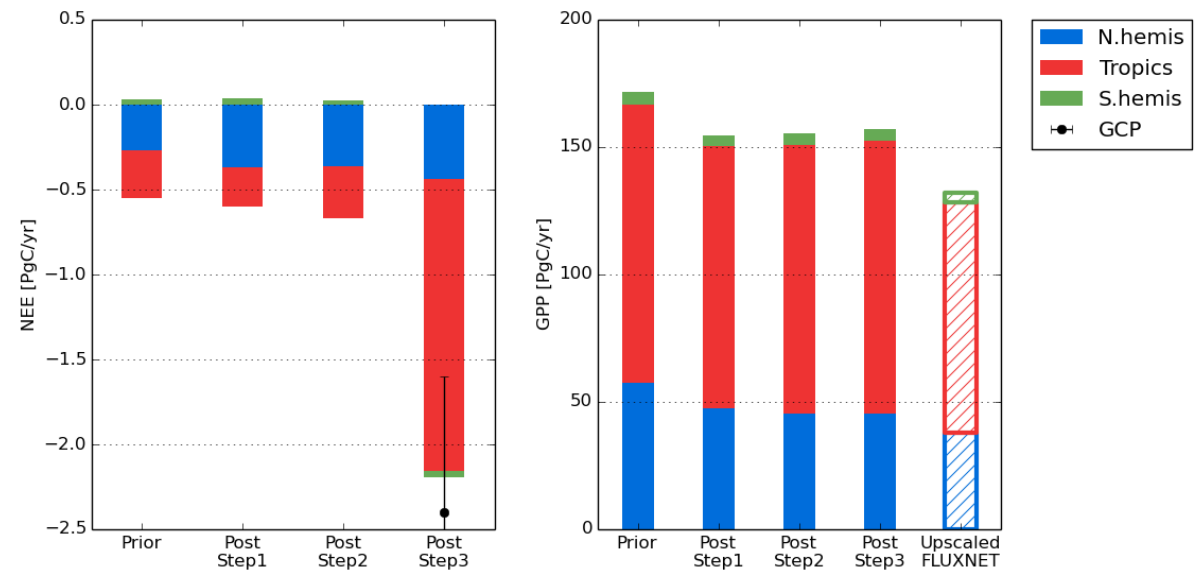

Figure 10. Left: net ecosystem exchange (NEE) for three regions (north of $35^{\circ} \mathrm{N}$, tropics, south of $35^{\circ} \mathrm{S}$ ) for the prior model, and after each step of the optimizations (mean over 2002-2004). The NEE estimate from the Global Carbon Project (GCP) for the same period (Le Quéré et al., 2015) is provided for step 3 with its error bar. Right: same but for gross primary production (GPP) where the data-driven estimate (MTE product using FluxNet data; Jung et al., 2011) is provided for comparison.

\subsubsection{Large-scale annual mean net fluxes}

The mean annual carbon fluxes (NEE) for the globe, northern extra tropics, tropics and southern extra tropics are reported in Fig. 10 for the 2000-2009 decade for the prior and posterior model simulations for all steps. We ran the optimized model over the full decade in the 2000s in order to compare with one other estimate of the land surface residual from the GCP (Le Quéré et al., 2015) over the same decade. The prior NEE indicates a total sink of $0.5 \mathrm{PgC} \mathrm{yr}^{-1}$ over this period, from both the northern and tropical regions. Such a prior sink is due to the increase of atmospheric $\mathrm{CO}_{2}$ during the transient simulation following the spin-up (1990-2009, see Sect. 2.3.1) and climate variability. Changes from the prior are rather small in step 1 (assimilation of MODIS NDVI) with an increase of the northern sink by $0.12 \mathrm{PgC} \mathrm{yr}^{-1}$ and a decrease of the tropical sink by $0.05 \mathrm{PgC} \mathrm{yr}^{-1}$ (Fig. 10). Step 2 (assimilation of FLUXNET data) does not significantly change the net $\mathrm{C}$ sink from step 1, with only a small increase in the tropical sink by $0.1 \mathrm{PgC} \mathrm{yr}^{-1}$. The assimilation of atmospheric $\mathrm{CO}_{2}$ data in step 3 provides a large-scale constraint, as already discussed, and increases the total land sink to $2.2 \mathrm{PgC} \mathrm{yr}^{-1}$, a value in much closer agreement with the estimate by the GCP. A larger tropical NEE uptake is responsible for the large increase of the terrestrial biosphere $\mathrm{C}$ sink (from $0.3 \mathrm{PgC} \mathrm{yr}^{-1}$ in step 2 to $1.7 \mathrm{PgC} \mathrm{yr}^{-1}$ ) while the sink in the north increases by less than $0.1 \mathrm{PgC} \mathrm{yr}^{-1}$. The comparison with the GCP number should be taken with caution. The ORCHIDAS estimated sink includes all effects (natural and anthropogenic), since we used atmospheric $\mathrm{CO}_{2}$ as a global constraint. Thus, the optimized parameters must account for any missing processes like nitrogen limitation or a proper description of agricultural processes and management. However, the GCP number is only for the anthropogenic uptake, excluding the pre-industrial sink due for instance to river export of carbon (around 0.45 $\mathrm{PgC} \mathrm{yr}^{-1}$; Regnier et al., 2013).

\subsubsection{Spatial distribution of the annual mean net flux}

Figure 11 shows the spatial distribution of NEE averaged over 2002-2004 for the standard prior and posterior after step 3. The large tropical net land carbon sink that is inferred in step 3 is mainly explained by an increase of the carbon uptake for the tropical forests of the Amazon basin and equatorial Africa, as well as a decrease of the carbon release on the southern edge of the Amazon basin (tropical rain-green forests and grasses). In the northern mid-to-high latitudes only smaller regional changes from the prior occur. For Europe, most of north Asia and Canada, the strength of the $\mathrm{C}$ sink slightly decreased from the prior (up to $30 \mathrm{~g} \mathrm{C} \mathrm{m}^{2} \mathrm{yr}^{-1}$ ), while for central USA the strength of C source slightly decreased. If we now consider the uncertainties on the net annual carbon flux that arise from the parameter uncertainty (second row of Fig. 11; Eq. 2), we observe a very large reduction (compared to the prior) in the monthly flux uncertainty (averaged over the 3 years used in step 3) over tropical forests. It is reduced by a factor 4 with initial values around $150 \mathrm{~g} \mathrm{C} \mathrm{m}^{2} \mathrm{yr}^{-1}$ and posterior values between 22 and $66 \mathrm{~g} \mathrm{C} \mathrm{m}^{2} \mathrm{yr}^{-1}$. For mid-to-high latitude boreal ecosystems, the uncertainty reduction is smaller, but the posterior errors are slightly lower than over the tropics, between 18 and $55 \mathrm{~g} \mathrm{C} \mathrm{m}^{2} \mathrm{yr}^{-1}$.

\subsubsection{Large-scale annual mean gross primary production}

For the GPP the relative changes from the prior are smaller than for the NEE (Fig. 10b). The mean annual total GPP is $172,155,156$ and $157 \mathrm{PgC} \mathrm{yr}^{-1}$ for the prior and poste- 

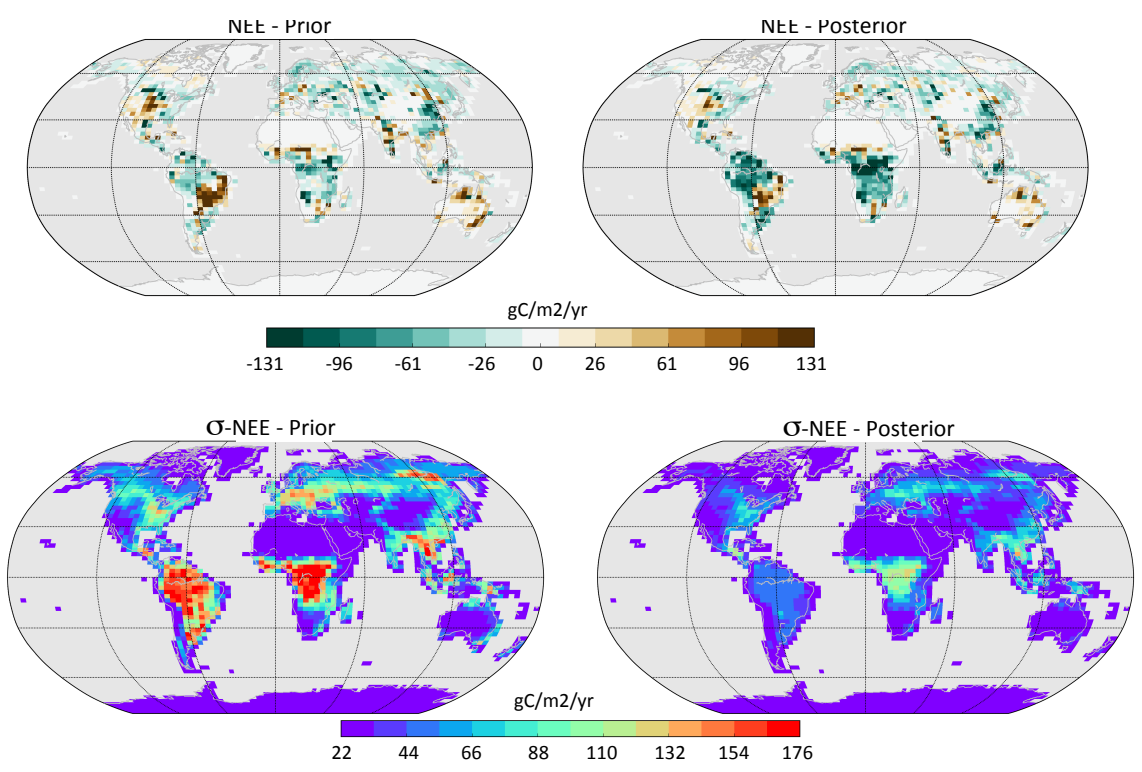

Figure 11. Simulated annual net carbon exchange (NEE) for the land ecosystems prior to any optimization (left column) and after step 3 of the optimization process (right column). Upper figures correspond to the mean NEE (in $\mathrm{g} \mathrm{C} \mathrm{m}^{-2} \mathrm{yr}^{-1}$ ) over the assimilation period (20012003) and lower figures to the associated monthly flux uncertainties (averaged over the whole period and expressed in $\mathrm{g} \mathrm{C} \mathrm{m}^{-2} \mathrm{yr}^{-1}$ ) due to the parameter uncertainties (see text).

rior of step 1, 2 and 3, respectively. The small overall decrease (9\%) brings the GPP slightly closer to the estimate by Jung et al. (2011), around $120 \mathrm{PgC} \mathrm{yr}^{-1}$, based on a statistical model tree ensemble (MTE) that upscaled the in situ flux measurements (resulting from the partition of measured NEE into GPP and total ecosystem respiration). The decrease in GPP occurs mainly in the Northern Hemisphere after step 1 $\left(-10 \mathrm{PgC}^{-1} \mathrm{r}^{-1}\right)$ following the decrease in $V_{\text {cmax }}$ (Fig. 9) while it remains relatively stable over the tropics across all steps. Note that (i) the study of Welp et al. (2011) suggests a GPP around $150 \mathrm{PgC} \mathrm{yr}^{-1}$, similar to our estimate, based on measurements of ${ }^{18} \mathrm{O} /{ }^{16} \mathrm{O}$ ratio in atmospheric $\mathrm{CO}_{2}$ and (ii) Koffi et al. (2012) found optimized GPP of $146 \mathrm{PgC} \mathrm{yr}^{-1}$ from a CCDAS using the BETHY model.

\subsubsection{Aboveground forest biomass}

We analyze the impact of the optimization on the forest aboveground biomass at equilibrium (i.e., after spin-up; see Fig. 12) as an example of the impact on model C stocks, and compare the simulated values, for the same three latitude bands than above, to the estimate based on field observations and remote sensing data. This product, which was produced in the GEOCARBON project (and thus is referred to by the same name), integrates a pan-tropical biomass map (Avitabile et al., 2016) with a boreal forest biomass product (Santoro et al., 2015).

For the northern extra tropics, the prior aboveground $\mathrm{C}$ stock $(\sim 180 \mathrm{PgC})$ is reduced by the optimization to $140 \mathrm{PgC}$, mainly through the decrease of the growing season length

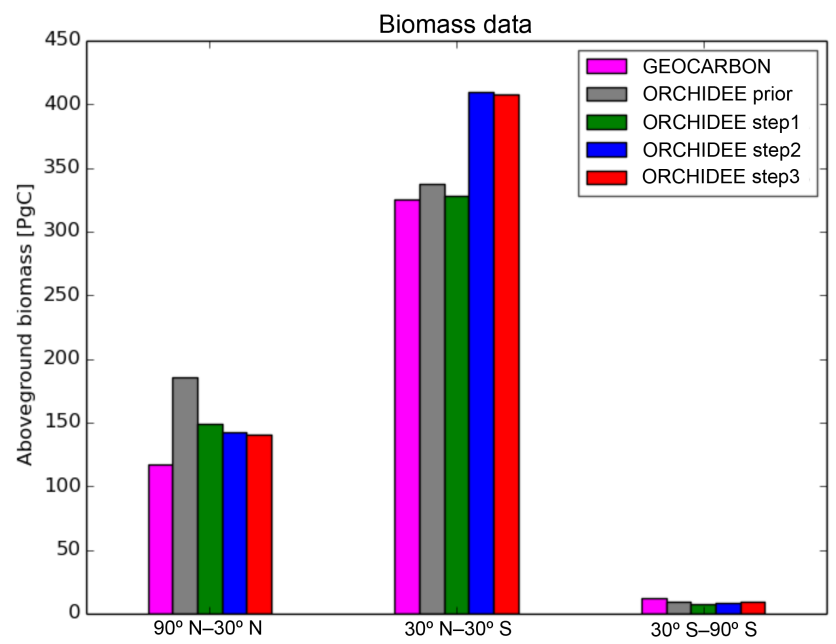

Figure 12. Aboveground forest biomass data for the prior ORCHIDEE model and after step 1, step 2 and step 3 of the optimization process. Estimates from satellite observations (Santoro et al., 2015) and referred as "GEOCARBON" (following the EUGEOCARBON project) are provided for comparison.

in step 1 with the assimilation of MODIS-NDVI. The significant decrease in GPP during step $1(18 \%)$ led indeed to a similar decrease of the forest biomass $(16 \%)$. Parameter changes through the assimilation of FLUXNET and $\mathrm{CO}_{2}$ data have a smaller impact (a change of less than $5 \mathrm{PgC}$ ). These changes in the northern extra tropics bring the estimates by the ORCHIDEE model closer to the satellite-based GEOCARBON product $(\sim 120 \mathrm{PgC})$. 
For the tropics, while there is nearly no change with the assimilation of MODIS-NDVI in step 1, the use of FLUXNET data leads to a significant increase of the forest aboveground biomass (close to $25 \%$ ). Such an increase does not correspond to an increase of the GPP (Fig. 10) but to changes in the autotrophic respiration parameter $\left(\mathrm{MR}_{b}\right)$ that lead to a decrease of autotrophic respiration and an increase of net primary production (NPP). The value does not change through step 3 and remains significantly higher than the data-driven estimate. Note however that the lower value in the GEOCARBON product could be partly due to the fact that we did not yet account for land use effects in the CCDAS, such as deforestation in the Amazon.

\section{Discussion and conclusions}

In this paper we have described a first global carbon cycle data assimilation system that assimilates three major carboncycle-related data streams, namely MODIS-NDVI observations of vegetation activity at 60 sites, FLUXNET NEE and LE measurements, at more than 70 sites, and atmospheric $\mathrm{CO}_{2}$ concentrations at 53 surface stations over 3 years in order to optimize the $\mathrm{C}$ cycle parameters of the ORCHIDEE process-based LSM (ORCHIDEE-CCDAS). The study details the concept, the implementation and the main results of a stepwise assimilation approach, where the data streams have been assimilated in three successive steps (including a propagation of the retrieved posterior parameter distributions from one step to the next).

The assimilation of MODIS-NDVI (60 grid-cell points, step 1) improved the phenology of ORCHIDEE with a significant reduction of the growing season length and thus a direct impact on the GPP. The results are similar to those presented in MacBean et al. (2015), who describe the impact of such optimization on the global FAPAR simulations and the improvement in the bias of the calculated leaf onset and senescence dates in more detail. The optimization with FLUXNET data (78 sites, step 2) led to large improvements in the seasonal cycle of the NEE and LE fluxes, constraining primarily the photosynthetic processes. Some discrepancies remain due to site heterogeneity (i.e., different species and edaphic conditions) that the model does not fully capture, and due to missing processes in the model (see Kuppel et al., 2014 for a more thorough discussion). However, without the assimilation of atmospheric $\mathrm{CO}_{2}$ concentrations, the global (and continental) net carbon balance after step 2 was still clearly outside the admitted range (as reported by the GCP in Le Quéré et al., 2015), which highlights the importance of assimilating a data stream such as this that provides information at larger scales (constraining large-scale respiration fluxes). The use of atmospheric $\mathrm{CO}_{2}$ concentration as an overall constraint in step 3 was technically challenging as it required the coupling of ORCHIDEE with an atmospheric transport model in forward and reverse mode (i.e., to com- pute the cost function and its gradients at each step of the minimization process). As a result of the final step, we were able to fit the atmospheric $\mathrm{CO}_{2}$ growth rate and thus to derive a land $\mathrm{C}$ sink compatible with current best estimates from the GCP. The assimilation of $\mathrm{CO}_{2}$ data also slightly changed the seasonality of the NEE, which improved the fit to the atmospheric $\mathrm{CO}_{2}$ seasonal cycle. Note that assimilating only $\mathrm{CO}_{2}$ data would lead to a similar global land $\mathrm{C}$ sink but with a different model parameter set not compatible with the information provided by MODIS-NDVI and FLUXNET data.

The consistency of the stepwise approach has been evaluated with back-compatibility checks after the final step (step 3: assimilation of atmospheric $\mathrm{CO}_{2}$ concentration). The optimized model with the final set of parameters does not degrade the fit to MODIS-NDVI and FLUXNET data that were assimilated in the first two steps (only minor changes of the RMSEs occur; see Fig. 8). This result has two important consequences. Most importantly it suggests that current state of the art LSMs (at least ORCHIDEE) have reached a level of development where consistent assimilation of multiple data streams is finally possible. This overcomes the most important limitation noted by Rayner (2010) to the widespread use of CCDAS systems. At a more technical level it suggests that stepwise assimilation is a valid and feasible approach. Although we only carried the estimated parameter uncertainties from one step to the next (as a first more simple approach), and not the full error variance-covariance matrix, we were able to propagate enough information to maintain an optimal model-data fit after the last step for the three data streams, as confirmed with the back-compatibility checks. MacBean et al. (2016a) provided a more specific analysis of this issue. However, not propagating the covariance terms may have a larger impact for the reduction of the inferred parameter uncertainties (see for instance the large parameter/flux error reduction in Fig. 9/Fig. 11). The order of the different steps was dictated by the number of parameters we choose to expose to each data stream, from only a few phenology parameters for NDVI up to the largest set for atmospheric $\mathrm{CO}_{2}$. Recall that under the fundamental theory the order of assimilation is unimportant. Testing whether our system meets this criterion is an important check on the robustness of the method but is not technically feasible with the full-blown system; it is currently being tested with some smaller models.

Most of the optimized parameter values have significantly changed compared to their prior values, with a large error reduction for most (Fig. 9) that results in a strong constraint on the simulated fluxes (Fig. 11). In the last step, the assimilation of atmospheric $\mathrm{CO}_{2}$ data mainly led to the optimization of respiration-related parameters, especially the regional soil carbon multipliers $\left(K_{\text {soilC,reg }}\right)$. Note that this was also the case for the BETHY-CCDAS, as described in Rayner et al. (2005) (see their Table 2). This is linked to the difficult issue of representing the effects of historical changes in land cover and land management as well as soil texture effects on soil carbon dynamics, and the necessary choice of a standard 
spin-up procedure to account for these effects. Ideally one would need to perform the optimization of the model over a long historical period with LULCC and land management practices included and the optimization of related parameters. However, this is not currently feasible at global scale and uncertainties in the forcing would introduce as much difficulty as uncertainties in the initial condition. The adjustment of the initial C pool contents is thus a logical compromise and further investigations into the impact of the selected setup (number of regions for $K_{\text {soilC,reg, their associated uncertain- }}$ ties) on the $\mathrm{C}$ fluxes simulated in the future are needed. Note that a first improvement would be to include LULCC in the transient simulation (to define the initial state) before the assimilation period.

Nonetheless, several limitations, inherent to the optimization of model parameters in a CCDAS, need to be called to mind when evaluating these results (see also Rayner, 2010). First, the structure of the land surface model (i.e., how biogeochemical processes are represented) is critical. Any missing/misrepresented processes may have a direct impact and thus lead to biases in the selected parameters. Note that this limitation could be even more severe when using atmospheric $\mathrm{CO}_{2}$ measurements, as these data provide a direct constraint on the overall net $\mathrm{C}$ exchange between the atmosphere and the vegetation, thus including all processes. As an example, the model sensitivity to atmospheric $\mathrm{CO}_{2}$ increase (e.g., through the parameters $V_{\text {cmax }}$ and $G_{s, \text { slope }}$ ) could be non-optimal as the current model version does not include explicit nitrogen and phosphorus limitations on photosynthesis. Second, the chosen set of observations does not provide specific constraints on long-term $\mathrm{C}$ processes such as tree mortality, disturbance effects or $\mathrm{C}$ allocation within a plant. For instance Fig. 12 illustrates that the optimized model may still significantly overestimate tropical forest biomass. The assimilation of aboveground biomass or soil carbon stock observations (i.e., site-level measurements or regional estimates) should thus provide critical complementary information (see Bloom et al., 2016 and Thum et al., 2016). Additionally, uncertainties on the other components of the carbon cycle, such as fossil fuel and biomass burning emissions and ocean fluxes, can be also critical when using atmospheric $\mathrm{CO}_{2}$ as a constraint. Finally, one can mention new approaches based on remote sensing data to account for site level differences in productivity potential due to edaphic variability (soil quality and slope/drainage) within the same vegetation type, as illustrated for high latitudes in North America (Ise and Sato, 2008).

To conclude, this work is a step forward in terms of multiple data streams assimilation that opens new perspectives for a better understanding of the carbon cycle and better predictions of the fate of the land carbon sink in the 21 st century as a consequence of anthropogenic changes. As ORCHIDEE is part of the IPSL Earth system model the impact of the optimization on future climate change predictions will be assessed in a future study. However, we first need to run the ORCHIDAS with a longer atmospheric $\mathrm{CO}_{2}$ record (i.e., several decades) in order to provide stronger constraints on parameters controlling the impact of climate extremes on the net carbon fluxes at continental to global scales, and the sensitivity of photosynthesis to increasing $\mathrm{CO}_{2}$ concentration. The optimized model will allow for a more in-depth investigation of the trend and interannual variations of land surface $\mathrm{C}$ fluxes at continental to regional scales, as well as their driving mechanisms. It will offer a more reliable and robust process-based diagnostic of the land $\mathrm{C}$ cycle that is compatible with current major data streams. Overall, we have illustrated the benefit of combining multiple data streams in a process-based model to optimize different processes of the model, related to different temporal and spatial scales. The optimization will be updated regularly as new processes are integrated into the ORCHIDEE model, such as for instance land management (Naudts et al., 2015).

\section{Code and data availability}

The ORCHIDEE model code and the run environment are open source (http://forge.ipsl.jussieu.fr/orchidee) and the associated documentation can be found at https://forge.ipsl. jussieu.fr/orchidee/wiki/Documentation. Note that the tangent linear version of the ORCHIDEE model has been generated using commercial software (TAF; http://www.fastopt. com/products/taf/taf.shtml). For this reason, only the "forward" version of the ORCHIDEE model is available for sharing. The optimization scheme (in Python) is available through a dedicated web site for data assimilation with ORCHIDEE (http://orchidas.lsce.ipsl.fr/). Nevertheless readers interested in running ORCHIDEE are encouraged to contact the corresponding author for full details and latest bug fixes. Finally, the source code of the LMDz atmospheric transport model can be downloaded from the following site: http:// lmdz.lmd.jussieu.fr/. The MODIS MOD09CMG collection 5 surface reflectance data are freely available to download from the Land Processes Distributed Active Archive Center (LP DAAC) data portal (https://lpdaac.usgs.gov, NASA LP DAAC, 2015). 


\section{Appendix A}

\section{A1 Ocean fluxes}

Figure A1 displays the air-sea fluxes from the statistical model.

\section{A2 Fire fluxes}

In order to account for fundamental differences between six fire flux categories provided by the GFED product, we grouped these emissions into three types with specific treatments. The first group includes $\mathrm{C}$ emissions from deforestation and peat fires, which are considered to be permanent carbon lost to the atmosphere, at least over the considered timescales. These fluxes are rescaled to an annual emission of $1.1 \mathrm{PgC} \mathrm{yr}^{-1}$ globally following typical values reported in the literature for deforestation (Houghton, 2003). The second group consists of $\mathrm{C}$ emissions from agriculture and savannah fires, which are compensated by a $\mathrm{C}$ sink during the regrowth of these biomes (i.e., savannah and some type of plants on the farmland). These effects are not completely accounted for in ORCHIDEE as the model does not simulate savannah and agriculture fire. Hence, the emissions over the whole period and for each pixel become zero, but their seasonal variations are used. The final group includes emissions from woodland and burnt forests. We considered that at steady state and for a given region certain forests burn but that nearby forests are re-growing following older fires. We thus imposed regrowth at the region scale given that the ORCHIDEE model version that we use does not account for such regrowth. The main assumption is that over century timescales the forest/woodland system is at steady state over a given region (few thousand $\mathrm{km}^{2}$ ); i.e., there is no net deforestation. We selected an ensemble of small regions over which we calculated the regrowth of these biomes. The derived emissions over the whole period and for each region thus become zero; however, we include their spatial and tem-

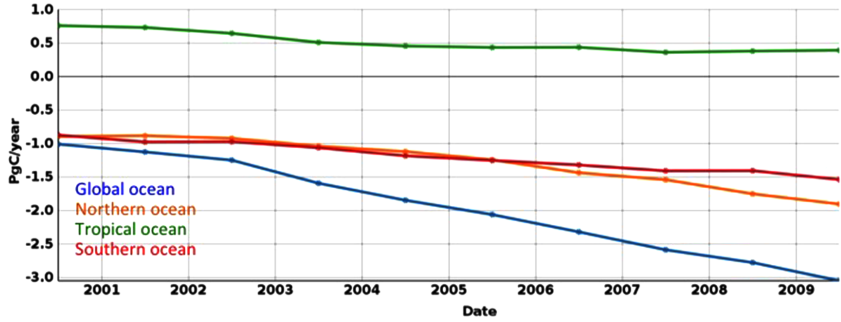

Figure A1. $\mathrm{CO}_{2}$ air-sea fluxes including the natural ocean outgazing, used as input to the ORCHIDEE-CCDAS and estimated from a neural network approach using observed $\mathrm{pCO}_{2}$ data (see main text, Sect. 2.5.1). The northern, tropical and southern ocean contributions to the global ocean flux (blue curve) are also provided.

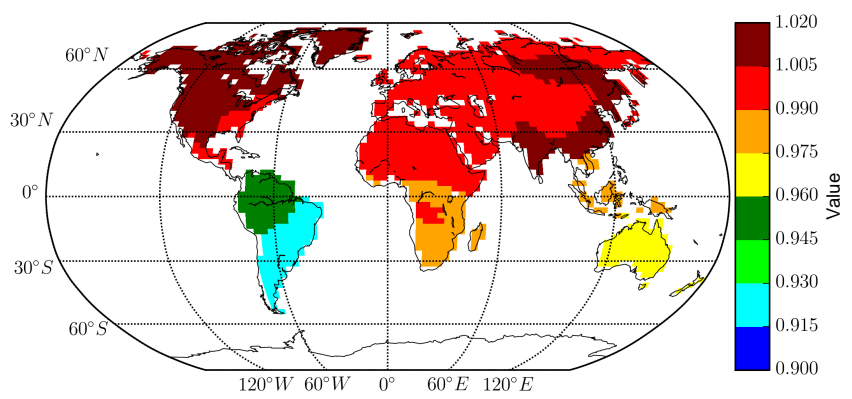

Figure A2. Map of the posterior values of the coefficient scaling the initial carbon pool sizes per regions.

poral variations. The overall biomass burning flux considered in the CCDAS for the optimization process is the sum of the three fluxes as described above.

\section{A3 Multipliers of the soil initial carbon pools}

Figure A2 provides the optimized values of the $K_{\text {soilC,reg }}$ parameters that optimize the initial soil carbon pool sizes. 
Acknowledgements. This work was mainly funded by the EU FP7 CARBONES project (contracts FP7-SPACE-2009-1-242316), with also a small contribution from GEOCARBON project (ENV.2011.4.1.1-1-283080). This work used eddy covariance data acquired by the FLUXNET community and in particular by the following networks: AmeriFlux (U.S. Department of Energy, Biological and Environmental Research, Terrestrial Carbon Program; DE-FG02-04ER63917 and DE-FG02-04ER63911), AfriFlux, AsiaFlux, CarboAfrica, CarboEuropeIP, CarboItaly, CarboMont, ChinaFlux, Fluxnet-Canada (supported by CFCAS, NSERC, BIOCAP, Environment Canada, and NRCan), GreenGrass, KoFlux, LBA, NECC, OzFlux, TCOS-Siberia, USCCC. We acknowledge the financial support to the eddy covariance data harmonization provided by CarboEuropeIP, FAO-GTOS-TCO, iLEAPS, Max Planck Institute for Biogeochemistry, National Science Foundation, University of Tuscia, Université Laval and Environment Canada and US Department of Energy and the database development and technical support from Berkeley Water Center, Lawrence Berkeley National Laboratory, Microsoft Research eScience, Oak Ridge National Laboratory, University of California-Berkeley, University of Virginia. Philippe Ciais acknowledges support from the European Research Council through Synergy grant ERC-2013-SyG-610028 “IMBALANCE-P”. The authors wish to thank M. Jung for providing access to the GPP MTE data, which were downloaded from the GEOCARBON data portal (https://www.bgc-jena.mpg.de/geodb/projects/Data.php). The authors are also grateful to computing support and resources provided at LSCE and to the overall ORCHIDEE project that coordinate the development of the code (http://labex.ipsl.fr/orchidee/index.php/about-the-team).

Edited by: J. Kala

Reviewed by: J.-F. Exbrayat and three anonymous referees

\section{References}

Alton, P. B.: From site-level to global simulation: Reconciling carbon, water and energy fluxes over different spatial scales using a process-based ecophysiological land-surface model, Agr. Forest Meteorol., 176, 111-124, doi:10.1016/j.agrformet.2013.03.010, 2013.

Avitabile, V., Herold, M., Heuvelink, G., Lewis, S. L., Phillips, O. L., Asner, G. P., Armston, J., Ashton, P. S., Banin, L., Bayol, N., Berry, N. J., Boeckx, P., De Jong, B. H. J., Devries, B., Girardin, C. A. J., Kearsley, E., Lindsell, J. A., Lopez-Gonzalez, G., Lucas, R., Malhi, Y., Morel, A., Mitchard, E. T. A., Nagy, L., Qie, L., Quinones, M. J., Ryan, C. M., Ferry, S. J. W., Sunderland, T., Vaglio Laurin, G., Cazzolla Gatti, R., Valentini, R., Verbeeck, H., Wijaya, A., and Willcock, S.: An integrated pan-tropical biomass map using multiple reference datasets. Glob. Change Biol., 22, 1406-1420, doi:10.1111/gcb.13139, 2016.

Bacour, C., Peylin, P., MacBean, N., Rayner, P. J., Delage, F., Chevallier, F., Weiss, M., Demarty, J., Santaren, D., Baret, F., Berveiller, D., Dufrêne, E., and Prunet, P.: Joint assimilation of eddy covariance flux measurements and FAPAR products over temperate forests within a process-oriented biosphere model, J. Geophys. Res.-Biogeo., 120, 1-19, doi:10.1002/2015JG002966, 2015.
Bloom, A. A., Exbrayat, J.-F., van der Velde, I. R., Feng, L., and Williams, M.: The decadal state of the terrestrial carbon cycle: Global retrievals of terrestrial carbon allocation, pools, and residence times, P. Natl. Acad. Sci. USA, 113, 1285-1290, doi:10.1073/pnas.1515160113, 2016.

Bousquet, P., Hauglustaine, D. A., Peylin, P., Carouge, C., and Ciais, P.: Two decades of $\mathrm{OH}$ variability as inferred by an inversion of atmospheric transport and chemistry of methyl chloroform, Atmos. Chem. Phys., 5, 2635-2656, doi:10.5194/acp-52635-2005, 2005.

Braswell, B. H., Sacks, W. J., Linder, E., and Schimel, D. S.: Estimating diurnal to annual ecosystem parameters by synthesis of a carbon flux model with eddy covariance net ecosystem exchange observations, Glob. Change Biol., 11, 335-355, doi:10.1111/j.1365-2486.2005.00897.x, 2005.

Byrd, R. H., Lu, P., Nocedal, J., and Zhu, C.: A limited memory algorithm for bound constrained optimization, SIAM J. Sci. Stat. Comput., 16, 1190-1208, 1995.

Canadell, J. G., Ciais, P., Sabine, C., and Joos, F. (Eds.): REgional Carbon Cycle Assessment and Processes (RECCAP), Special issue, Biogeosciences, http://www.biogeosciences-discuss.net/ special_issue83.html, 2013.

Chevallier, F., Fisher, M., Peylin, P., Serrar, S., Bousquet, P., Bréon, F.-M., Chédin, A., and Ciais, P.: Inferring $\mathrm{CO}_{2}$ sources and sinks from satellite observations: Method and application to TOVS data, J. Geophys. Res., 110, D24309, doi:10.1029/2005JD006390, 2005.

Chevallier, F., Ciais, P., Conway, T. J., Aalto, T., Anderson, B. E., Bousquet, P., Brunke, E. G., Ciattaglia, L., Esaki, Y., Fröhlich, M., Gomez, A. J., Gomez-Pelaez, A. J., Haszpra, L., Krummel, P., Langenfelds, R., Leuenberger, M., Machida, T., Maignan, F., Matsueda, H., Morguí, J. A., Mukai, H., Nakazawa, T., Peylin, P., Ramonet, M., Rivier, L., Sawa, Y., Schmidt, M., Steele, P., Vay, S. A., Vermeulen, A. T., Wofsy, S., and Worthy, D.: $\mathrm{CO}_{2}$ surface fluxes at grid point scale estimated from a global 21-year reanalysis of atmospheric measurements, J. Geophys. Res., 115, D21307, doi:10.1029/2010JD013887, 2010.

Collatz, G. J., Ribas-Carbo, M., and Berry, J. A.: Coupled Photosynthesis-Stomatal Conductance Model for Leaves of C4 Plants, Aust. J. Plant Physiol., 19, 519-538, 1992.

Dee, D. P., Uppala, S. M., Simmons, A. J., Berrisford, P., Poli, P., Kobayashi, S., Andrae, U., Balmaseda, M. A., Balsamo, G., Bauer, P., Bechtold, P., Beljaars, A. C. M., van de Berg, L., Bidlot, J., Bormann, N., Delsol, C., Dragani, R., Fuentes, M., Geer, A. J., Haimberger, L., Healy, S. B., Hersbach, H., Hólm, E. V., Isaksen, L., Kållberg, P., Köhler, M., Matricardi, M., Mcnally, A. P., Monge-Sanz, B. M., Morcrette, J. J., Park, B. K., Peubey, C., de Rosnay, P., Tavolato, C., Thépaut, J. N., and Vitart, F.: The ERA-interim reanalysis: configuration and performance of the data assimilation system, Q. J. Roy. Meteor. Soc., 137, 553-597, doi:10.1002/qj.828, 2011.

D'Odorico, P., Gonsamo, A., Pinty, B., Gobron, N., Coops, N., Mendez, E., and Schaepman, M. E.: Intercomparison of fraction of absorbed photosynthetically active radiation products derived from satellite data over Europe, Remote Sens. Environ., 142, 141-154, 2014.

Ducoudré, N. I., Laval, K., and Perrier, A.: Sechiba, a New Set of Parameterizations of the Hydrologic Exchanges at the Land 
Atmosphere Interface within the Lmd Atmospheric GeneralCirculation Model, J. Climate, 6, 248-273, 1993.

Dufresne, J. L., Foujols, M. A., Denvil, S., et al.: Climate change projections using the IPSL-CM5 Earth System Model: from CMIP3 to CMIP5, Clim. Dynam., 40, 2123-2165, 2013.

Farquhar, G. D., von Caemmerer, S., and Berry, J. A.: A biochemical model of photosynthetic $\mathrm{CO}_{2}$ assimilation in leaves of $\mathrm{C}_{3}$ species, Planta, 149, 78-90, 1980.

Folberth, G., Hauglustaine, D. A., Ciais, P., and Lathiere, J.: On the role of atmospheric chemistry in the global $\mathrm{CO}_{2}$ budget, Geophys. Res. Lett., 32, L08801, doi:10.1029/2004GL021812, 2005.

Fung, I. Y., Tucker, C. J., and Prentice, K. C.: Application of Advanced Very High Resolution Radiometer vegetation index to study atmosphere - biosphere exchange of $\mathrm{CO}_{2}$, J. Geophys. Res., 92, 2999-3015, 1987.

GLOBALVIEW: Cooperative Global Atmospheric Data Integration Project, updated annually, Multi-laboratory compilation of synchronized and gap-filled atmospheric carbon dioxide records for the period 1979-2012 (obspack_co2_1_GLOBALVIEWCO2_2013_v1.0.4_2013-12-23), compiled by NOAA Global Monitoring Division: Boulder, Colorado, USA Data product: doi:10.3334/OBSPACK/1002, 2013.

Groenendijk, M., Dolman, A. J., van der Molen, M. K., Leuning, R., Arneth, A., Delpierre, N., Gash, J. H. C., Lindroth, A., Richardson, A. D., Verbeeck, H., and Wohlfahrt, G.: Assessing parameter variability in a photosynthesis model within and between plant functional types using global Fluxnet eddy covariance data, Agr. Forest Meteorol., 151, 22-38, doi:10.1016/j.agrformet.2010.08.013, 2011.

Hauglustaine, D. A., Hourdin, F., Jourdain, L., Filiberti, M. A., Walters, S., Lamarque, J. F., and Holland, E. A.: Interactive chemistry in the Laboratoire de Meteorologie Dynamique general circulation model: Description and background tropospheric chemistry evaluation, J. Geophys. Res.-Atmos., 109, D04314, doi:10.1029/2003JD003957, 2004.

Houghton, R. A.: Revised estimates of the annual net flux of carbon to the atmosphere from changes in land use and land management 1850-2000, Tellus, 55B, 378-390, 2003.

Hourdin, F. and Armengaud, A.: The use of finite-volume methods for atmospheric advection of trace species. Part I: Test of various formulations in a general circulation model, Mon. Weather Rev., 127, 822-837, 1999 .

Hourdin, F., Musat, I., Bony, S., Braconnot, P., Codron, F., Dufresne, J.-L., Fairhead, L., Filiberti, M.-A., Friedlingstein, P., Grandpeix, J.-Y., Krinner, G., LeVan, P., Li, Z.-X., and Lott, F.: The LMDZ4 general circulation model: climate performance and sensitivity to parametrized physics with emphasis on tropical convection, Clim. Dynam., 27, 787-813, 2006.

IPCC: Climate Change 2007: The Physical Science Basis. Contribution of Working Group I to the Fourth Assessment Report of the Intergovernmental Panel on Climate Change, edited by: Solomon, S., Qin, D., and Manning, M., Cambridge University Press, Cambridge, UK, 2007.

Ise, T. and Sato, H.: Representing subgrid-scale edaphic heterogeneity in a largescale ecosystem model: A case study in the circumpolar boreal regions, Geophys. Res. Lett., 35, L20407, doi:10.1029/2008GL035701, 2008.

Jung, M., Reichstein, M., Margolis, H. A., Cescatti, A., Richardson, A. D., Arain, M. A., Arneth, A., Bernhofer, C., Bonal, D., Chen
J., Gianelle, D., Gobron, N., Kiely, G., Kutsch, W., Lasslop, G., Law, E. B., Lindroth, A., Merbold, L., Montagnani, L., Moors, E. J., Papale, D., Sottocornola, M., Vaccari, F., and Williams, C.: Global patterns of land-atmosphere fluxes of carbon dioxide, latent heat, and sensible heat derived from eddy covariance, satellite, and meteorological observations, J. Geophys. Res.-Biogeo., 116, G00J07, doi:10.1029/2010JG001566, 2011.

Kaminski, T., Knorr, W., Rayner, P. J., and Heimann, M.: Assimilating atmospheric data into a terrestrial biosphere model: A case study of the seasonal cycle, Global Biogeochem. Cy., 16, 1066, doi:10.1029/2001GB001463, 2002.

Kaminski, T., Knorr, W., Scholze, M., Gobron, N., Pinty, B., Giering, R., and Mathieu, P.-P.: Consistent assimilation of MERIS FAPAR and atmospheric $\mathrm{CO}_{2}$ into a terrestrial vegetation model and interactive mission benefit analysis, Biogeosciences, 9, 3173-3184, doi:10.5194/bg-9-3173-2012, 2012.

Kaminski, T., Knorr, W., Schürmann, G., Scholze, M., Rayner, P. J., Zaehle, S., Blessing, S., Dorigo, W., Gayler, V., Giering, R., Gobron, N., Grant, J. P., Heimann, M., Hooker-Stroud, A., Houweling, S., Kato, T., Kattge, J., Kelley, D., Kemp, S., Koffi, E. N., Köstler, C., Mathieu, P. P., Pinty, B., Reick, C. H., Rödenbeck, C., Schnur, R., Scipal, K., Sebald, C., Stacke, T., Van Scheltinga, A. T., Vossbeck, M., Widmann, H., and Ziehn, T.: The BETHY/JSBACH Carbon Cycle Data Assimilation System: Experiences and challenges, J. Geophys. Res.-Biogeo., 118, 1414-1426, doi:10.1002/jgrg.20118, 2013.

Kato, T., Knorr, W., Scholze, M., Veenendaal, E., Kaminski, T., Kattge, J., and Gobron, N.: Simultaneous assimilation of satellite and eddy covariance data for improving terrestrial water and carbon simulations at a semi-arid woodland site in Botswana, Biogeosciences, 10, 789-802, doi:10.5194/bg-10-789-2013, 2013.

Kattge, J., Diaz, S., Lavorel, S., et al.: TRY - a global database of plant traits, Glob. Change Biol., 17, 2905-2935, 2011.

Keenan, T. F., Davidson, E., Moffat, A. M., Munger, W., and Richardson, A. D.: Using model-data fusion to interpret past trends, and quantify uncertainties in future projections, of terrestrial ecosystem carbon cycling, Glob. Change Biol., 18, 25552569, doi:10.1111/j.1365-2486.2012.02684.x, 2012.

Keenan, T. F., Davidson, E. A., Munger, J. W., and Richardson, A. D.: Rate my data: Quantifying the value of ecological data for the development of models of the terrestrial carbon cycle, Ecol. Appl., 23, 273-286, doi:10.1890/12-0747.1, 2013.

Knorr, W. and Heimann, M.: Impact of drought stress and other factors on seasonal land biosphere $\mathrm{CO}_{2}$ exchange studied through an atmospheric tracer transport model, Tellus B, 47, 471-489, 1995.

Knorr, W. and Kattge, J.: Inversion of terrestrial ecosystem model parameter values against eddy covariance measurements by Monte Carlo sampling, Glob. Change Biol., 11, 1333-1351, doi:10.1111/j.1365-2486.2005.00977.x, 2005.

Knyazikhin, Y., Martonchik, J. V., Myneni, R. B., Diner, D. J., and Running, S. W.: Synergistic algorithm for estimating vegetation canopy leaf area index and fraction of absorbed photosynthetically active radiation from MODIS and MISR, J. Geophys. Res., 103, 32257-32276, 1998.

Koffi, E. N., Rayner, P. J., Scholze, M., and Beer, C.: Atmospheric constraints on gross primary productivity and net ecosystem productivity: Results from a carbon-cycle data as- 
similation system, Global Biogeochem. Cy., 26, GB1024, doi:10.1029/2010GB003900, 2012.

Krinner, G., Viovy, N., de Noblet-Ducoudré, N., Ogée, J., Polcher, J., Friedlingstein, P., Ciais, P., Sitch, S., and Prentice, I. C.: A dynamic global vegetation model for studies of the coupled atmosphere-biosphere system, Global Biogeochem. Cy., 19, GB1015, doi:10.1029/2003GB002199, 2005.

Kuppel, S., Peylin, P., Chevallier, F., Bacour, C., Maignan, F., and Richardson, A. D.: Constraining a global ecosystem model with multi-site eddy-covariance data, Biogeosciences, 9, 3757-3776, doi:10.5194/bg-9-3757-2012, 2012.

Kuppel, S., Chevallier, F., and Peylin, P.: Quantifying the model structural error in carbon cycle data assimilation systems, Geosci. Model Dev., 6, 45-55, doi:10.5194/gmd-6-45-2013, 2013.

Kuppel, S., Peylin, P., Maignan, F., Chevallier, F., Kiely, G., Montagnani, L., and Cescatti, A.: Model-data fusion across ecosystems: from multisite optimizations to global simulations, Geosci. Model Dev., 7, 2581-2597, doi:10.5194/gmd-7-25812014, 2014.

Lasslop, G., Reichstein, M., Kattge, J., and Papale, D.: Influences of observation errors in eddy flux data on inverse model parameter estimation, Biogeosciences, 5, 1311-1324, doi:10.5194/bg5-1311-2008, 2008.

Le Quéré, C., Moriarty, R., Andrew, R. M., Peters, G. P., Ciais, P., Friedlingstein, P., Jones, S. D., Sitch, S., Tans, P., Arneth, A., Boden, T. A., Bopp, L., Bozec, Y., Canadell, J. G., Chini, L. P., Chevallier, F., Cosca, C. E., Harris, I., Hoppema, M., Houghton, R. A., House, J. I., Jain, A. K., Johannessen, T., Kato, E., Keeling, R. F., Kitidis, V., Klein Goldewijk, K., Koven, C., Landa, C. S., Landschützer, P., Lenton, A., Lima, I. D., Marland, G., Mathis, J. T., Metzl, N., Nojiri, Y., Olsen, A., Ono, T., Peng, S., Peters, W., Pfeil, B., Poulter, B., Raupach, M. R., Regnier, P., Rödenbeck, C., Saito, S., Salisbury, J. E., Schuster, U., Schwinger, J., Séférian, R., Segschneider, J., Steinhoff, T., Stocker, B. D., Sutton, A. J., Takahashi, T., Tilbrook, B., van der Werf, G. R., Viovy, N., Wang, Y.-P., Wanninkhof, R., Wiltshire, A., and Zeng, N.: Global carbon budget 2014, Earth Syst. Sci. Data, 7, 47-85, doi:10.5194/essd-7-47-2015, 2015.

MacBean, N., Maignan, F., Peylin, P., Bacour, C., Bréon, F.-M., and Ciais, P.: Using satellite data to improve the leaf phenology of a global terrestrial biosphere model, Biogeosciences, 12, 71857208, doi:10.5194/bg-12-7185-2015, 2015.

MacBean, N., Peylin, P., Chevallier, F., Scholze, M., and Schürmann, G.: Consistent assimilation of multiple data streams in a carbon cycle data assimilation system, Geosci. Model Dev. Discuss., doi:10.5194/gmd-2016-25, in review, 2016.

Madec, G., Delecluse, P., Imbard, M., and Lévy, C.: OPA 8.1 Ocean General Circulation Model reference manual, Note du Pole de Modelisation, Institut Pierre-Simon Laplace, 11, Laboratoire d'Océanographie Dynamique et de Climatologie, Paris, France, 91 pp., 1998.

Maignan, F., Bréon, F.-M., Chevallier, F., Viovy, N., Ciais, P., Garrec, C., Trules, J., and Mancip, M.: Evaluation of a Global Vegetation Model using time series of satellite vegetation indices, Geosci. Model Dev., 4, 1103-1114, doi:10.5194/gmd-4-11032011, 2011.

Moore, D. J. P., Hu, J., Sacks, W. J., Schimel, D. S., and Monson, R. K.: Estimating transpiration and the sensitivity of car- bon uptake to water availability in a subalpine forest using a simple ecosystem process model informed by measured net $\mathrm{CO}_{2}$ and $\mathrm{H}_{2} \mathrm{O}$ fluxes, Agr. Forest Meteorol., 148, 1467-1477, doi:10.1016/j.agrformet.2008.04.013, 2008.

Morris, M. D.: Factorial sampling plans for preliminary computational experiments, Technometrics, 33, 161-174, 1991.

NASA LP DAAC: Surface Reflectance Daily L3 Global 0.05Deg CMG. Version 5. NASA EOSDIS Land Processes DAAC, USGS Earth Resources Observation and Science (EROS) Center, Sioux Falls, South Dakota, USA, available at: https://lpdaac.usgs.gov, last access: 1 January 2015.

Naudts, K., Ryder, J., McGrath, M. J., Otto, J., Chen, Y., Valade, A., Bellasen, V., Berhongaray, G., Bönisch, G., Campioli, M., Ghattas, J., De Groote, T., Haverd, V., Kattge, J., MacBean, N., Maignan, F., Merilä, P., Penuelas, J., Peylin, P., Pinty, B., Pretzsch, H., Schulze, E. D., Solyga, D., Vuichard, N., Yan, Y., and Luyssaert, S.: A vertically discretised canopy description for ORCHIDEE (SVN r2290) and the modifications to the energy, water and carbon fluxes, Geosci. Model Dev., 8, 2035-2065, doi:10.5194/gmd-8-2035-2015, 2015.

Olivier, J. G., Peters, J. A., and Janssens-Maenhout, G.: Trends in global $\mathrm{CO}_{2}$ emissions 2012 report, PBL Netherlands Environmental Assessment Agency, The Hague/Bilthoven, the Netherlands, doi:10.2788/33777, 2012.

Papale, D.: Towards a standardized processing of Net Ecosystem Exchange measured with eddy covariance technique: algorithms and uncertainty estimation, available at: http://dspace.unitus.it/ handle/2067/1321 (last access: 1 September 2016), 2006.

Parton, W., Stewart, J., and Cole, C.: Dynamics of C, N, P and S in grassland soils: a model, Biogeochemistry, 5, 109-131, 1988.

Peylin, P., Rayner, P. J., Bousquet, P., Carouge, C., Hourdin, F., Heinrich, P., Ciais, P., and AEROCARB contributors: Daily $\mathrm{CO}_{2}$ flux estimates over Europe from continuous atmospheric measurements: 1. inverse methodology, Atmos. Chem. Phys., 5, 3173-3186, doi:10.5194/acp-5-3173-2005, 2005.

Piao, S., Sitch, S., Ciais, P., Friedlingstein, P., Peylin, P., Wang, X., Ahlström, A., Anav, A., Canadell, J. G., Cong, N., Huntingford, C., Jung, M., Levis, S., Levy, P. E., Li, J., Lin, X., Lomas, M. R., Lu, M., Luo, Y., Ma, Y., Myneni, R. B., Poulter, B., Sun, Z., Wang, T., Viovy, N., Zaehle, S., and Zeng, N.: Evaluation of terrestrial carbon cycle models for their response to climate variability and to $\mathrm{CO}_{2}$ trends, Glob. Change Biol., 19, 2117-2132, doi:10.1111/gcb.12187, 2013.

Prentice, I. C., Liang, X., Medlyn, B. E., and Wang, Y.-P.: Reliable, robust and realistic: the three R's of next-generation land-surface modelling, Atmos. Chem. Phys., 15, 5987-6005, doi:10.5194/acp-15-5987-2015, 2015.

Raoult, N. M., Jupp, T. E., Cox, P. M., and Luke, C. M.: Landsurface parameter optimisation using data assimilation techniques: the adJULES system V1.0, Geosci. Model Dev., 9, 28332852, doi:10.5194/gmd-9-2833-2016, 2016.

Rayner, P. J.: The current state of carbon-cycle data assimilation, Current Opinion in Environmental Sustainability, 2, 289-296, 2010.

Rayner, P. J., Scholze, M., Knorr, W., Kaminski, T., Giering, R., and Widmann, H.: Two decades of terrestrial carbon fluxes from a carbon cycle data assimilation system (CCDAS), Global Biogeochem. Cy., 19, GB2026, doi:10.1029/2004GB002254, 2005. 
Regnier, P., Friedlingstein, P., Ciais, P., Mackenzie, F. T., Gruber, N., Janssens, I. A., Laruelle, G. G., Lauerwald, R., Luyssaert, S., Andersson, A. J., Arndt, S., Arnosti, C., Borges, A. V., Dale, A. W., Gallego-Sala, A., Goddéris, Y., Goossens, N., Hartmann, J., Heinze, C., Ilyina, T., Joos, F., LaRowe, D. E., Leifeld, J., Meysman, F. J. R., Munhoven, G., Raymond, P. A., Spahni, R., Suntharalingam, P., and Thullner, M.: Anthropogenic perturbation of the carbon fluxes from land to ocean, Nat. Geosci., 6, 597-607, 2013.

Ricciuto, D. M., Butler, M. P., Davis, K. J., Cook, B. D., Bakwin, P. S., Andrews, A., and Teclaw, R. M.: Causes of interannual variability in ecosystem-atmosphere $\mathrm{CO}_{2}$ exchange in a northern Wisconsin forest using a Bayesian model calibration, Agr. Forest Meteorol., 148, 309-327, doi:10.1016/j.agrformet.2007.08.007, 2008.

Ricciuto, D. M., King, A. W., Dragoni, D., and Post, W. M.: Parameter and prediction uncertainty in an optimized terrestrial carbon cycle model: Effects of constraining variables and data record length, J. Geophys. Res., 116, G01033, doi:10.1029/2010JG001400, 2011.

Richardson, A. D., Williams, M., Hollinger, D. Y., Moore, D. J. P., Dail, D. B., Davidson, E. A., Scott, N. A., Evans, R. S., Hughes, H., Lee, J. T., Rodrigues, C., and Savage, K.: Estimating parameters of a forest ecosystem $\mathrm{C}$ model with measurements of stocks and fluxes as joint constraints, Oecologia, 164, 25-40, doi:10.1007/s00442-010-1628-y, 2010.

Rivier L., Ciais P., Hauglustaine D. A., Bakwin, P., Bousquet, P., Peylin, P., and Klonecki, A.: Evaluation of $\mathrm{SF}_{6}, \mathrm{C}_{2} \mathrm{Cl}_{4}$, and $\mathrm{CO}$ to approximate fossil fuel $\mathrm{CO}_{2}$ in the Northern Hemisphere using a chemistry transport model, J. Geophys. Res.-Atmos., 111, D16311, doi:10.1029/2005JD006725, 2006.

Rödenbeck, C., Bakker, D. C. E., Gruber, N., Iida, Y., Jacobson, A. R., Jones, S., Landschützer, P., Metzl, N., Nakaoka, S., Olsen, A., Park, G.-H., Peylin, P., Rodgers, K. B., Sasse, T. P., Schuster, U., Shutler, J. D., Valsala, V., Wanninkhof, R., and Zeng, J.: Data-based estimates of the ocean carbon sink variability first results of the Surface Ocean $p \mathrm{CO}_{2}$ Mapping intercomparison (SOCOM), Biogeosciences, 12, 7251-7278, doi:10.5194/bg12-7251-2015, 2015.

Rosenblatt, F.: The perceptron: a probabilistic model for information storage and organization in the brain, Psychol. Rev., 65, 386408, doi:10.1037/h0042519, 1958

Sabine, C. L., Feely, R. A., Gruber, N., Key, R. M., Lee, K., Bullister, J. L., Wanninkhof, R., Wong, C. S., Wallace, D. W. R., Tilbrook, B., Millero, F. J., Peng, T.-H., Kozyr, A., Ono, T., and Rios, A. F.: The oceanic sink for anthropogenic $\mathrm{CO}_{2}$, Science, 305, 367-371, 2004.

Saito, M., Ito, A., and Maksyutov, S.: Optimization of a prognostic biosphere model for terrestrial biomass and atmospheric $\mathrm{CO}_{2}$ variability, Geosci. Model Dev., 7, 1829-1840, doi:10.5194/gmd-7-1829-2014, 2014.

Santaren, D., Peylin, P., Bacour, C., Ciais, P., and Longdoz, B.: Ecosystem model optimization using in situ flux observations: benefit of Monte Carlo versus variational schemes and analyses of the year-to-year model performances, Biogeosciences, 11, 7137-7158, doi:10.5194/bg-11-7137-2014, 2014.

Santoro, M., Beaudoin, A., Beer, C., Cartus, O., Fransson, J. E., Hall, R. J., Pathe, C., Schmullius, C., Schepaschenko, D., Shvidenko, A., Thurner, M., and Wegmüller, U.: Forest growing stock volume of the northern hemisphere: Spatially explicit estimates for 2010 derived from Envisat ASAR, Remote Sens. Environ., 168, 316-334, 2015.

Schürmann, G. J., Kaminski, T., Köstler, C., Carvalhais, N., Voßbeck, M., Kattge, J., Giering, R., Rödenbeck, C., Heimann, M., and Zaehle, S.: Constraining a land surface model with multiple observations by application of the MPI-Carbon Cycle Data Assimilation System, Geosci. Model Dev. Discuss., doi:10.5194/gmd-2015-263, in review, 2016.

Sitch, S., Friedlingstein, P., Gruber, N., Jones, S. D., MurrayTortarolo, G., Ahlström, A., Doney, S. C., Graven, H., Heinze, C., Huntingford, C., Levis, S., Levy, P. E., Lomas, M., Poulter, B., Viovy, N., Zaehle, S., Zeng, N., Arneth, A., Bonan, G., Bopp, L., Canadell, J. G., Chevallier, F., Ciais, P., Ellis, R., Gloor, M., Peylin, P., Piao, S. L., Le Quéré, C., Smith, B., Zhu, Z., and Myneni, R.: Recent trends and drivers of regional sources and sinks of carbon dioxide, Biogeosciences, 12, 653679, doi:10.5194/bg-12-653-2015, 2015.

Takahashi, T., Sutherland, S. C., Wanninkhof, R., Sweeney, C., Feely, R. A., Chipman, D. W., Hales, B., Friederich, G., Chavez, F., Sabine, C., Watson, A., Bakker, D. C. E., Schuster, U., Metzl, N., Yoshikawa-Inoue, H., Ishii, M., Midorikawa, T., Nojiri, Y., Körtzinger, A., Steinhoff, T., Hoppema, M., Olafsson, J., Arnarson, T. S., Tilbrook, B., Johannessen, T., Olsen, A., Bellerby, R., Wong, C. S., Delille, B., Bates, N. R., and de Baar, H. J. W.: Corrigendum to "Climatological mean and decadal change in surface ocean $p \mathrm{CO}_{2}$, and net sea-air $\mathrm{CO}_{2}$ flux over the global oceans", Deep-Sea Res. Pt. II, 56, 554-577, 2009.

Tarantola, A.: Inverse problem theory: Methods for data fitting and parameter estimation, Elsevier, Amsterdam, the Netherlands, 1987.

Tarantola, A.: Inverse problem theory and methods for model parameters estimation, ISBN 0-89871-572-5, Society for Industrial and Applied Mathematics, Philadelphia, USA, 2005.

Thoning, K. W., Tans, P. P., and Komhyr, W. D.: Atmospheric carbon dioxide at Mauna Loa Observatory: 2. Analysis of the NOAA GMCC data, 1974-1985, J. Geophys. Res., 94, 85498565, 1989.

Thum, T., MacBean, N., Peylin, P., Bacour, C., Santaren, D., Longdoz, B., Loustau, D., and Ciais, P., The potential of forest biomass data in addition to carbon and water flux measurements to constrain ecosystem model parameters: Case studies at two temperate forest sites, Agr. Forest Meteorol., in revision, 2016.

Tiedtke, M.: A comprehensive mass flux scheme for cumulus parameterization in large-scale models, Mon. Weather Rev., 117, 1779-1800, 1989.

Uppala, S. M., Kållberg, P. W., Simmons, A. J., et al.: The ERA-40 re-analysis, Q. J. Roy. Meteor. Soc., 131, 2961-3012, 2005.

Vérant, S., Laval, K., Polcher, J., and De Castro, M.: Sensitivity of the continental hydrological cycle to the spatial resolution over the Iberian Peninsula, J. Hydrometeorol., 5, 267-285, 2004.

Vermote, E., Justice, C. O., and Breon, F.-M.: Towards a generalized approach for correction of the BRDF effect in MODIS directional reflectances, IEEE T. Geosci. Remote, 47, 898-908, 2009.

Wang, Y. P., Leuning, R., Cleugh, H., and Coppin, P.: Parameter estimation in surface exchange models using nonlinear inversion: how many parameters can we estimate and which mea- 
surements are most useful?, Glob. Change Biol., 7, 495-510, doi:10.1046/j.1365-2486.2001.00434.x, 2001.

Wang, Y. P., Baldocchi, D., Leuning, R., Falge, E., and Vesala, T.: Estimating parameters in a land-surface model by applying nonlinear inversion to eddy covariance flux measurements from eight FLUXNET sites, Glob. Change Biol., 13, 652-670, doi:10.1111/j.1365-2486.2006.01225.x, 2007.

Wanninkhof, R.: Relationship between wind speed and gas exchange, J. Geophys. Res., 97, 7373-7382, 1992.

Weiss, R. F.: Carbon dioxide in water and seawater: the solubility of a non-ideal gas, Mar. Chem., 2, 203-215, 1974.

Welp, L. R., Keeling, R. F., Meijer, H. A., Bollenbacher, A. F., Piper, S. C., Yoshimura, K., Francey, R. J., Allison, C. E., and Wahlen, M.: Interannual variability in the oxygen isotopes of atmospheric $\mathrm{CO}_{2}$ driven by El Nino, Nature, 477, 579-582, 2011.

Williams, M., Schwarz, P. A., Law, B. E., Irvine, J., and Kurpius, M. R.: An improved analysis of forest carbon dynamics using data assimilation, Glob. Change Biol., 11, 89-105, doi:10.1111/j.1365-2486.2004.00891.x, 2005.
Xiao, J., Davis, K. J., Urban, N. M., and Keller, K.: Uncertainty in model parameters and regional carbon fluxes: A modeldata fusion approach, Agr. Forest Meteorol., 189-190, 175-186, doi:10.1016/j.agrformet.2014.01.022, 2014.

Yapo, P. O., Gupta, H. V., and Sorooshian, S.: Multi-objective global optimization for hydrologic models, J. Hydrol., 204, 8397, 1998.

Zobitz, J. M., Moore, D. J. P., Quaife, T., Braswell, B. H., Bergeson, A., Anthony, J. A., and Monson, R. K.: Joint data assimilation of satellite reflectance and net ecosystem exchange data constrains ecosystem carbon fluxes at a high-elevation subalpine forest, Agr. Forest Meteorol., 195-196, 73-88, 2014. 